\title{
Effect of Fucoxanthinol on Pancreatic Ductal Adenocarcinoma Cells from an $N$-Nitrosobis(2-oxopropyl)amine-initiated Syrian Golden Hamster Pancreatic Carcinogenesis Model
}

\author{
MASARU TERASAKI ${ }^{1,2}$, YUSAKU NISHIZAKA ${ }^{1}$, WATARU MURASE ${ }^{1}$, ATSUHITO KUBOTA $^{1}$, \\ HIROYUKI KOJIMA $^{1,2}$, MARESHIGE KOJOMA ${ }^{1}$, TAKUJI TANAKA ${ }^{3}$, HAYATO MAEDA ${ }^{4}$, \\ KAZUO MIYASHITA ${ }^{5}$, MICHIHIRO MUTOH ${ }^{6}$ and MAMI TAKAHASHI ${ }^{7}$ \\ ${ }^{1}$ School of Pharmaceutical Sciences and ${ }^{2}$ Advanced Research Promotion Center, \\ Health Sciences University of Hokkaido, Hokkaido, Japan; \\ ${ }^{3}$ Department of Diagnostic Pathology and Research Center of Diagnostic Pathology, \\ Gifu Municipal Hospital, Gifu, Japan; \\ ${ }^{4}$ Faculty of Agriculture and Life Science, Hirosaki University, Aomori, Japan; \\ ${ }^{5}$ Center for Industry-University Collaboration, \\ Obihiro University of Agriculture and Veterinary Medicine, Obihiro, Japan; \\ ${ }^{6}$ Department of Molecular-Targeting Prevention, Graduate School of Medical Science, \\ Kyoto Prefectural University of Medicine, Kyoto, Japan; \\ ${ }^{7}$ Central Animal Division, National Cancer Center, Tokyo, Japan
}

\begin{abstract}
Background/Aim: Fucoxanthinol (FxOH) is a marine carotenoid metabolite with potent anti-cancer activity. However, little is known about the efficacy of $\mathrm{FxOH}$ in pancreatic cancer. In the present study, we investigated the inhibitory effect of $\mathrm{FxOH}$ on six types of cells cloned from $\mathrm{N}$ nitrosobis(2-oxopropyl)amine (BOP)-induced hamster pancreatic cancer (HaPC) cells. Materials and Methods: $\mathrm{FxOH}$ action and its molecular mechanisms were investigated in HaPC cells using flow-cytometry, comprehensive gene array, and western blotting analyses. Results: $\mathrm{FxOH}(5.0 \mu \mathrm{M})$ significantly suppressed the growth of four out of six types of HaPC cells. Moreover, FxOH significantly suppressed cell cycle, chemokine, integrin, actin polymerization, microtubule organization and PI3K/AKT and TGF- $\beta$ signals, and activated caspase-3 followed by apoptosis and anoikis induction in HaPC-5 cells. Conclusion: FxOH may have a high potential
\end{abstract}

This article is freely accessible online.

Correspondence to: Masaru Terasaki, School of Pharmaceutical Sciences and Cancer Prevention Laboratories, Health Sciences University of Hokkaido, 1757 Kanazawa, Ishikari-Tobetsu, Hokkaido 061-0293, Japan. Tel: +81 133231211 ext. 3156, e-mail: terasaki@hoku-iryo-u.ac.jp

Key Words: Apoptosis, carotenoid, fucoxanthinol, hamster pancreatic cancer, CXCR7. as a cancer chemopreventive agent in a hamster pancreatic carcinogenesis model.

Pancreatic cancer is one of the most lethal cancers worldwide because it is treatment resistant and has aggressive potential for metastasis/invasion with resultant poor prognosis. From the GLOBOCAN 2018 estimates, 432,242 pancreatic cancer deaths occur per year (4.5\% of total) (1), and the 5-year survival rate remains poor at $10 \%$ (2). Accumulating evidence suggests that aberrant network integrity of gene mutation, gene methylation, transcriptome, microRNA, non-coding RNA, proteome, tumor microenvironment, and immune cells are crucial for human pancreatic cancer development. In particular, highly carcinogenic point mutations in driver genes, such as KRAS, CDKN2A, TP53, and SMAD4, are observed in many specimens (3-7). Pancreatic intraepithelial neoplasia (PanIN) is a premalignant lesion in pancreatic carcinogenesis and has the stepwise progress graded as four types from mild to severe. KRAS, CDKN2A, TP53 and SMAD4 are somatically mutated in turn along with the malignant progression of PanIN, followed by the cancer progression (8).

$N$-nitrosobis(2-oxopropyl)amine (BOP)-treated Syrian golden hamsters are a chemical carcinogenesis model that represents human pancreatic cancer because it induces PanIN, and pancreatic ductal adenocarcinoma resembles human pancreatic cancer, which also includes similar genetic mutations such as in $K$-ras, CDKN2A, and SMAD4 (9). Therefore, the BOP-induced hamster pancreatic cancer 
model is a useful model to investigate the mechanism of carcinogenesis and in the identification of chemopreventive agents against pancreatic cancer. Several cancer prevention experiments using BOP-treated hamsters revealed that natural dietary materials, such as fermented brown rice, 4methylthio-3-butenyl isothiocyanate, benzyl isothiocyanate, sulforaphane, green tea polyphenols, and $\beta$-carotene may be candidate cancer chemopreventive agents; however, the anticancer mechanisms involved remain elusive (10-13).

Fucoxanthin (Fx) is a highly polar carotenoid that has a distinctive allene and a 5,6-monoepoxide. Fx predominantly accumulates in marine brown algae, some of which are used in foods. Dietary Fx is converted to its deacetylated form fucoxanthinol $(\mathrm{FxOH})$ mainly in the intestine of humans as well as in mice $(14,15)$.

To date, human interventional studies aimed at preventing cancer with Fx or FxOH have been limited. On the other hand, many reports have shown that Fx has anti-cancer activity in various cancers in vitro and in vivo (16-23). Regarding $\mathrm{FxOH}$, it suppressed tumorigenesis in immunodeficient NOD-SCID mice (24). It also induced apoptosis in colon cancer cells and colon cancer stem-like spheroids through attenuation of integrin, mitogen-activated protein kinase (MAPK), nuclear factor- $\mathrm{kB}$, phosphatidylinositol-3 kinase/protein kinase B (PI3K/AKT), peroxisome proliferator-activated receptor, signal transducers and activators of transcription (STAT), chloride intracellular channel 4 (CLIC4), and caspase signaling (25-28). These molecules are also involved in migration, invasion, epithelial-mesenchymal transition, and cell-cycle arrest. However, little information in available on the anti-cancer function of $\mathrm{FxOH}$ in pancreatic cancer.

Herein, we showed the apoptosis-inducing effect of $\mathrm{FxOH}$ on a cell line cloned from pancreatic ductal adenocarcinoma in a BOP-treated hamster and elucidated its molecular mechanisms.

\section{Materials and Methods}

Chemicals. All-trans-FxOH (purity, $\geq 98 \%$ ) was extracted and purified from algal lipids by Dr. Hayato Maeda (Hirosaki University, Japan). Anti-C-X-C chemokine receptor type 4 (CXCR4) and anti-CXCR7 antibodies were purchased from BioVision (Milpitas, CA, USA) and Novus Biologicals (Littleton, CO, USA), respectively. Anti-Akt (pan), anti-cyclin B1, antiphosphorylated focal adhesion kinase [pFAK $\left.\left(\mathrm{Tyr}^{397}\right)\right]$, anti-integrin $\alpha 5$, anti-integrin $\beta 1$, anti-integrin $\beta 4$, and anti-caspase- 3 antibodies were obtained from GeneTex (Irvine, CA, USA). Anti-cyclin D1,

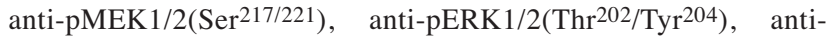
pAkt(Ser $\left.{ }^{473}\right)$, and anti-pAkt $\left(\mathrm{Thr}^{308}\right)$ antibodies were from Cell Signaling Technology (Danvers, MA, USA). Anti-cyclin D2 and anti-integrin $\beta 8$ antibodies were purchased from Bioss Antibodies (Beijing, PR China) and R\&D Systems (Minneapolis, MN, USA), respectively. Anti-pPaxillin $\left(\mathrm{Tyr}^{31}\right)$ and anti-p53 antibodies were obtained from Novex (San Diego, CA, USA) and Thermo Scientific (Waltham, MA, USA), respectively. The cells were routinely maintained in Dulbecco's modified Eagle medium (DMEM, Wako Pure Chemicals, Osaka, Japan) containing 10\% heat-inactivated fetal bovine serum (FBS), $4 \mathrm{mM} \mathrm{L-glutamine,} \mathrm{40,000} \mathrm{U/1} \mathrm{penicillin,}$ and $40 \mathrm{mg} / \mathrm{l}$ streptomycin. All other reagents and solvents used were of analytical grade.

Establishment of cell lines. Female Syrian golden hamsters (5-weekold, Japan SLC, Shizuoka, Japan) were acclimated for a week and injected subcutaneously with BOP (Nacalai Tesque, Kyoto, Japan) 4 times (on days 1, 3, 5, and 7) at a dose of $10 \mathrm{mg} / \mathrm{kg}$ body weight. CE-2 pellets (CLEA Japan, Shizuoka, Japan) were used as a standard diet, and 1 group of hamsters was fed Quick Fat pellets (QF) (CLEA Japan, Shizuoka, Japan). Hamsters were sacrificed with deep anesthesia at 38-90 weeks of age, and then the pancreas from each hamster was taken and part of the tumor collected. Most pancreatic tissue was placed in $10 \%$ formalin/phosphate-buffered saline for 2-3 days. Histopathologic diagnosis of pancreatic tissue in the hamster was performed by a highly proficient pathologist. The animal experiments were approved by the Institutional Guidelines for Animal Care and Use in the National Cancer Center Research Institute

The tumor sections were minced using scissor and cultured in 5\% FBS/RPMI-1640 (Wako Pure Chemicals, Osaka, Japan) medium in 24-well plates. When the cultured cells reached confluence, they were seeded in another dish (6-well plates), and then in a larger dish (100-mm in diameter). The established cell lines were designated hamster pancreatic cancer (HaPC)-1, -2, -3, - 4 , and -5 derived from a hamster given CE-2, and HaPC-6 from a hamster given QF.

Cell viability assay. HaPC-1-6 cells were adhered at a density of $5 \times 10^{4}$ cells/ml into a 24 -well plate in $10 \%$ FBS/DMEM medium for $3.5 \mathrm{~h}$. Cells were then incubated in 1\% FBS/DMEM medium with $\mathrm{FxOH}$ (final concentrations, 1.0 and $5.0 \mu \mathrm{M}$ ) or vehicle alone [dimethylsulfoxide (DMSO)] for 1 day. Cell viability was determined using a WST-1 reagent assay. The absorbance was monitored using an ELISA reader at $450 \mathrm{~nm}$ (TECAN Japan, Tokyo, Japan).

Cell cycle analysis. HaPC-5 cells were adhered at a density of $5 \times 10^{4}$ cells $/ \mathrm{ml}$ into $100-\mathrm{mm}$ dishes in $10 \% \mathrm{FBS} / \mathrm{DMEM}$ medium for $3.5 \mathrm{~h}$. Cells were then incubated in 1\% FBS/DMEM medium with $\mathrm{FxOH}$ (final concentration, $5.0 \mu \mathrm{M}$ ) or vehicle alone (DMSO) for 2 days. The cells were trypsinized, fixed with $70 \%$ ethanol, and then treated with ribonuclease A (Nacalai Tesque, Kyoto, Japan). Nuclei in the cells were stained with propidium iodide (SigmaAldrich, St Louis, MO, USA), and the cells were suspended with $0.1 \%$ bovine serum albumin (BSA)/phosphate-buffered saline. The ratios of Sub- $\mathrm{G}_{1}$ (apoptosis-like cells), $\mathrm{G}_{1}, \mathrm{~S}$, and $\mathrm{G}_{2} / \mathrm{M}$ phases were determined using a FACSAria-III flow cytometer (BD Biosciences).

Total RNA preparation. HaPC-5 cells were adhered at a density of $5 \times 10^{4}$ cells $/ \mathrm{ml}$ into $100-\mathrm{mm}$ dishes in $10 \% \mathrm{FBS} / \mathrm{DMEM}$ medium for $3.5 \mathrm{~h}$. Cells were then incubated in 1\% FBS/DMEM medium with $\mathrm{FxOH}$ (final concentration, $5.0 \mu \mathrm{M}$ ) or vehicle alone (DMSO) for 1 day. Total RNA from HaPC-5 cells with or without $5.0 \mu \mathrm{M}$ FxOH treatment was isolated using an RNeasy Mini Kit with RNase-Free DNase Set and QIAshredder (QIAGEN, Valencia, CA, USA) in accordance with the manufacturer's instructions. The concentration of total RNA was measured using Nanodrop ND-1000 (NanoDrop, Wilmington, DE, USA). Subsequently, quantitation of total RNA was determined using an Agilent 2100 bioanalyzer 
(Agilent, Santa Clara, USA). Total RNA from FxOH-treated HaPC5 cells or control cells was prepared as a sample with equivalently mixed mRNAs with triplicate experiments and then subjected to next-generation sequencing.

Transcriptome analysis. Whole transcriptome analysis was performed in accordance with the TruSeq Standard mRNA Reference Guide Document \#1000000040498 v00 and the next generation sequencer NovaSeq 6000 System User Guide Document \#1000000019358 v02. In brief, total RNA was purified into mRNA, fragmented, and then prepared as double-stranded cDNA. Subsequently, libraries from the cDNA template were prepared using a TruSeq standard mRNA LT Sample Prep kit (Illumina, San Diego, CA, USA) and sequenced using a NovaSeq 6000 S4 Reagent kit (Illumina, San Diego, CA, USA). The sequencing was carried out using a NovaSeq 6000 system (Illumina, San Diego, CA, USA) equipped with sequencing control software (version 1.4.0). Differentially expressed genes between FxOH-treated HaPC5 cells and the control cells were detected using $\geq 2.0$ - and $\leq-2.0$-fold cutoff and $p$-values $<0.05$ (exact test using edgeR). Gene profiles were displayed using volcano plots and hierarchy clustering maps. Gene annotation was performed using the NCBI reference sequence database Mesocricetus auratus Annotation Release 102 (ncbi.nlm. nih.gov/genome/annotation_euk/Mesocricetus_auratus/102/). Functional interpretation analysis was performed using the g:Profiler tool (https://biit.cs.ut.ee/gprofiler), based on the gene ontology (GO) database (http://www.geneontology.org/).

Quantitative-polymerase chain reaction ( $q P C R)$. The cDNA was synthesized from total RNA using a High Capacity cDNA Reverse Transcription kit (Thermo Fisher Scientific, Waltham, MA). Gene primer and probe sequences were as follows: Ackr3-forward (5'AGG TAG GTA TCA GGC AGA G-3'), Ackr3-reverse (5'-CAG CAC CTC CAG CTA TAA GAA G-3'), glyceraldehyde-3-phosphate dehydrogenase $(G A P D H)$-forward (5'-GTT GGA ACC CAG TGC ATA GA-3'), GAPDH-reverse (5'-GGG TGT GAA CCA TGA CAA GTA-3'), Ackr3 probe (5'-/56-FAM/TGT TGT CTG/ZEN/CAT CTT GGT GTG GCT/31ABkFQ/-3') and GAPDH probe (5'-/56FAM/CTG CAC CAC/ZEN/CAA CTG GCT GAA ATG/31ABkFQ/3') (Integrated DNA Technologies, Coralville, IA).

The cDNA template $(10 \mathrm{ng}$ ), primers (final $500 \mathrm{pM}$ )/probe (final $250 \mathrm{pM}$ ) sets (Integrated DNA Technologies, Coralville, IA, USA), PrimeTime Gene Expression Master Mix (Integrated DNA Technologies), and distilled water were mixed (total volume, $20 \mu \mathrm{l}$ ). qPCR was performed as follows: initial denaturation for $5 \mathrm{~min}$ at $95^{\circ} \mathrm{C}$, followed by 40 cycles of $15 \mathrm{~s}$ at $95^{\circ} \mathrm{C}$ and $45 \mathrm{~s}$ at $60^{\circ} \mathrm{C}$. qPCR was performed using a LightCycler ${ }^{\circledR}$ Nano real-time PCR system (Roche Diagnostics, Mannheim, Germany).

Western blotting. HaPC- 5 cells were adhered at a density of $5 \times 10^{4}$ cells $/ \mathrm{ml}$ in $100-\mathrm{mm}$ dishes in $10 \%$ FBS/DMEM medium for $3.5 \mathrm{~h}$. Cells were then incubated in 1\% FBS/DMEM medium with FxOH (final concentration, $5.0 \mu \mathrm{M}$ ) or vehicle alone (DMSO) for 1 day. HaPC-5 cells with or without 5.0 $\mu \mathrm{M} \mathrm{FxOH}$ treatment were harvested and lysed in lysis buffer. The protein concentration in whole cell lysates was determined using the Bradford assay (BioRad, Hercules, CA, USA). Ten $\mu \mathrm{g}$ of protein was separated using a sodium dodecyl sulfate-10\% polyacrylamide gel. Gels were electroblotted onto a PVDF membrane (Amersham Bioscience, Chalfont St. Giles, UK). The membrane was incubated in Tris- buffered saline containing $0.1 \%$ polyoxyethylene (20) sorbitan monolaurate with $1 \%$ BSA (1\% BSA/Tris-buffered saline containing $0.1 \%$ Tween 20 [TBS-T]) at room temperature for $1 \mathrm{~h}$, and probed with each of the primary antibodies (1:1,000 dilution) in $1 \%$ BSA/TBS-T at $4^{\circ} \mathrm{C}$ overnight. The membranes were then probed with horseradish peroxidase-conjugated anti-mouse or anti-rabbit secondary antibody (1:2,000 dilution) in 1\% BSA/TBS-T at room temperature for $1 \mathrm{~h}$. Protein bands were visualized using a chemiluminescence reagent (Millipore, Billerica, MA, USA).

Statistics analysis. All the values are expressed as the mean \pm standard error (SE). All differences were examined using the Student's $t$-test or exact test with edgeR between two groups, and one-way ANOVA with Tukey-Kramer post-hoc tests for multiple comparisons. Significant differences were presented at $* p<0.05$, $* * p<0.01$ or exact $p$-values.

\section{Results}

Characterization of six types of pancreatic ductal adenocarcinoma cancers in BOP-treated hamster. Pathological findings revealed that several types of pancreatic cancers exist in BOP-treated hamsters. These were pathologically diagnosed as papillary adenocarcinoma, well differentiated tubular adenocarcinoma, moderately differentiated tubular adenocarcinoma, and poorly differentiated adenocarcinoma. These cells cloned from the six types of pancreatic adenocarcinomas were designated as HaPC-1-6 (Figure 1 and Table I).

Effect of FxOH on cell growth in HaPC-1-6 cells. The growth of $\mathrm{HaPC}-1,-4,-5$, and -6 cells was significantly decreased in a dose-dependent manner by $\mathrm{FxOH}$ treatment. Little significant difference in the cell growth of HaPC-2 and -3 cells was observed with $\mathrm{FxOH}$ treatment. The percentages of cell growth (control 100\%) were as follows: $1.0 \mu \mathrm{M}$ $\mathrm{FxOH}, 89.8 \pm 2.8 \% ; 5.0 \mu \mathrm{M}$ FxOH, $88.3 \pm 2.0 \%$ in HaPC-1

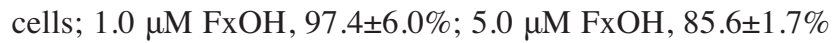
in HaPC-4 cells; $1.0 \mu \mathrm{M}$ FxOH, 82.5 $2.8 \%$; $5.0 \mu \mathrm{M}$ FxOH, $76.6 \pm 2.2 \%$ in HaPC-5 cells; and $1.0 \mu \mathrm{M} \mathrm{FxOH}, 98.0 \pm 1.1 \%$; $5.0 \mu \mathrm{M}$ FxOH, $93.1 \pm 2.0 \%$ in HaPC-6 cells (Figure 2).

Effect of FxOH on apoptosis induction and cell-cycle arrest in HaPC-5 cells. Treatment of HaPC-5 cells with $5.0 \mu \mathrm{M}$ $\mathrm{FxOH}$ showed drastic morphological changes from an elongated cell form to a thin spindle form (Figure 3A). Treatment with 5.0 $\mu \mathrm{M}$ FxOH significantly augmented the

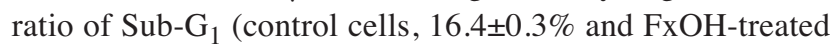
cells, $32.3 \pm 2.0 \%$ ) in HaPC-5 cells. The ratio of HaPC-5 cells in each cell cycle phase was significantly changed by $5.0 \mu \mathrm{M}$ FxOH treatment: $\mathrm{G}_{0} / \mathrm{G}_{1}$ phase, control cells, $65.8 \pm 0.1 \%$ and FxOH-treated cells, $71.7 \pm 0.4 \% ; \mathrm{G}_{2} / \mathrm{M}$ phase, control cells, $15.0 \pm 0.2 \%$ and FxOH-treated cells, $10.0 \pm 0.4 \%$. The proportion of HaPC-5 cells in $\mathrm{S}$ phase did not significantly differ between control and FxOH-treated cells (Figure 3B). 


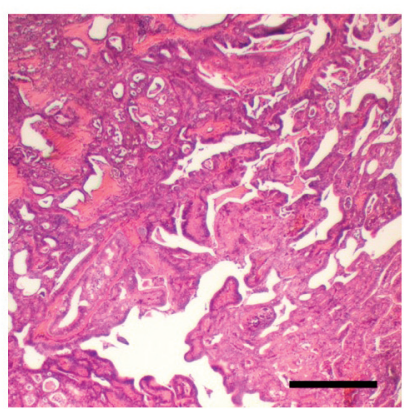

ADC-1

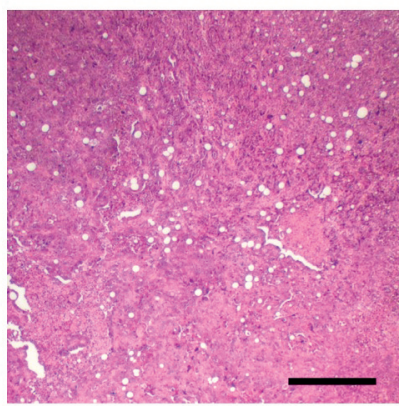

ADC-4

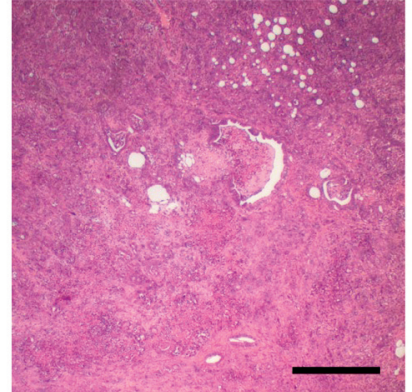

ADC-2

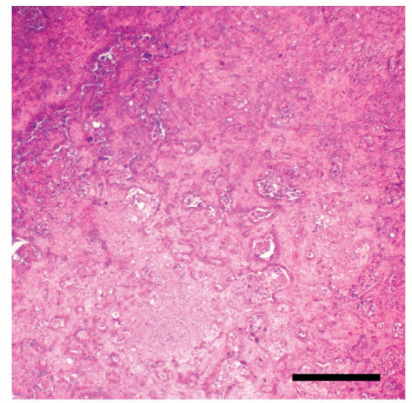

ADC-5

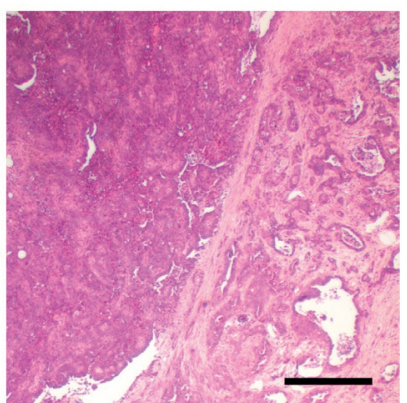

ADC-3

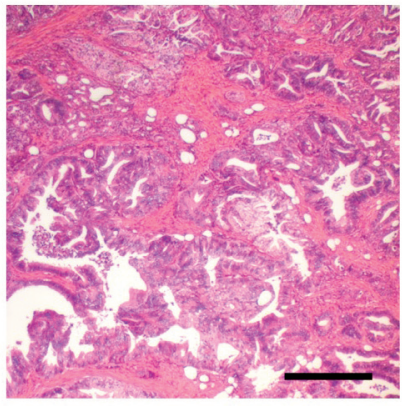

ADC-6

Figure 1. Representative histopathology of six pancreatic ductal adenocarcinomas developed in BOP-treated hamsters. ADC, adenocarcinoma. Bar, $400 \mu \mathrm{m}$.

Effect of $\mathrm{FxOH}$ on the transcriptome in HaPC-5 cells. Transcriptome alterations in HaPC-5 cells after 5.0 $\mu \mathrm{M}$ FxOH treatment for 1 day were investigated. As a result, volcano plots showed that the number of down-regulated genes was greater than that of up-regulated genes in both fold-change and $p$-value (Figure 4A). Heat maps were used to display one-way hierarchical clustering of the 1,213 genes that showed differences between the two groups (Figure 4B). Overall, 344 up-regulated and 869 downregulated genes (total 1,213 genes) were altered in $\mathrm{FxOH}-$ treated HaPC-5 cells compared to control cells (Figure 4C). The top 16 GO terms for biological processes and $1 \mathrm{GO}$ term for cellular components were significantly enriched in the 344 up-regulated genes. The genes in the GO terms on response to hormone (15 genes), taxis (13 genes), muscle tissue development (11 genes), and euchromatin (4 genes) were mainly associated with growth and inflammation, although few up-regulated genes involved in apoptosis induction were observed (Figure 5 and Table II). The genes for cellular response to hormone stimulus and chemotaxis are not shown in Table II, because the genes contained in these were similar for responses to hormone and chemotaxis, respectively. The top $20 \mathrm{GO}$ terms for biological processes and cellular components and the top 12
Table I. Pathological findings for six cell lines cloned from pancreatic ductal adenocarcinoma of BOP-initiated Hamster.

\begin{tabular}{lccc}
\hline Hamsterno. & Adenocarcinoma & Feature & Cell line $^{\mathrm{a}}$ \\
\hline 1 & 1 & $\begin{array}{c}\text { Pap ADC } \\
\text { Tub2 } 2^{\mathrm{c}}>>\text { Por }\end{array}$ & HaPC-1 \\
1 & 2 & Por & HaPC-2 \\
1 & 3 & Por $>>$ Pap ADC & HaPC-3 \\
1 & 4 & Por $>>$ Tub2 & HaPC-4 \\
1 & 5 & Tub2 $>>$ Por & HaPC-5 \\
2 & 6 & Tub2 $>>$ Tube & HaPC-6 \\
\hline
\end{tabular}

BOP, $N$-Nitrosobis(2-oxopropyl)amine; HaPC, Hamster pancreatic cancer. aName of cell lines cloned from each pancreatic tumor. ${ }^{b} \mathrm{Pap}$ ADC, papillary adenocarcinoma. ${ }^{\mathrm{c} T u b 2}$, moderately differentiated tubular adenocarcinoma. ${ }^{\mathrm{d}}$ Por, poorly differentiated adenocarcinoma. eTub1, well differentiated tubular adenocarcinoma.

GO terms for molecular function were significantly enriched in the 869 down-regulated genes. The GO terms for mitotic cell-cycle process (53 genes), cell surface (33 genes), supramolecular polymer (30 genes), supramolecular complex (30 genes), supramolecular fiber organization (33 genes), tubulin binding ( 21 genes), and microtubule binding 

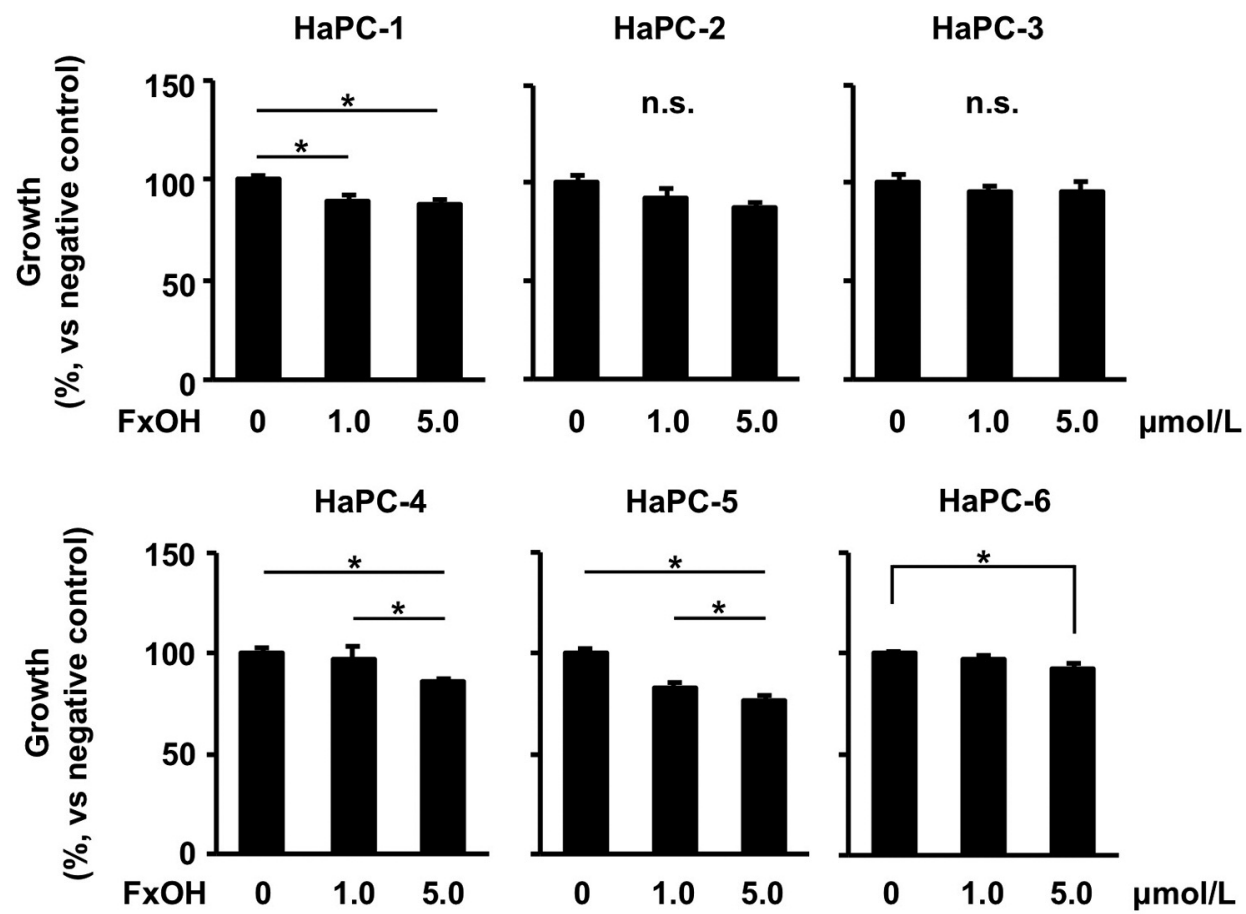

Figure 2. Effects of fucoxanthinol (FxOH) on cell growth in pancreatic cancer HaPC-1-6 cells. HaPC-1-6 cells were treated with 1.0 and $5.0 \mu \mathrm{M}$ FXOH for 1 day. Cell viability was measured using WST-1 reagent assay. The cell viability of control cells was set as 100\%. Means \pm SE ( $n=6)$. $* p<0.05$ vs. control cells (vehicle only).

A

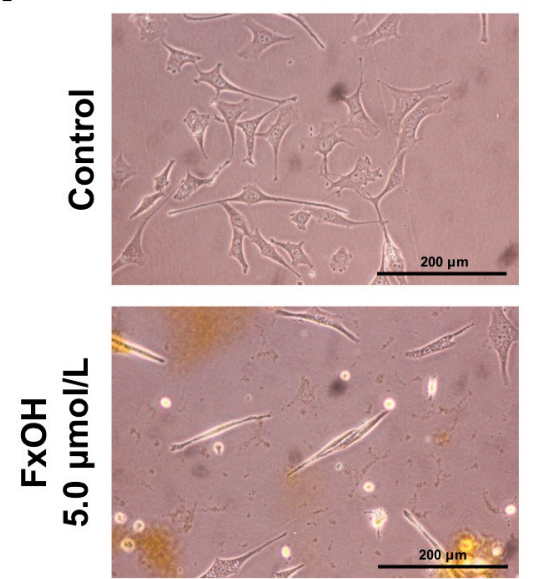

B

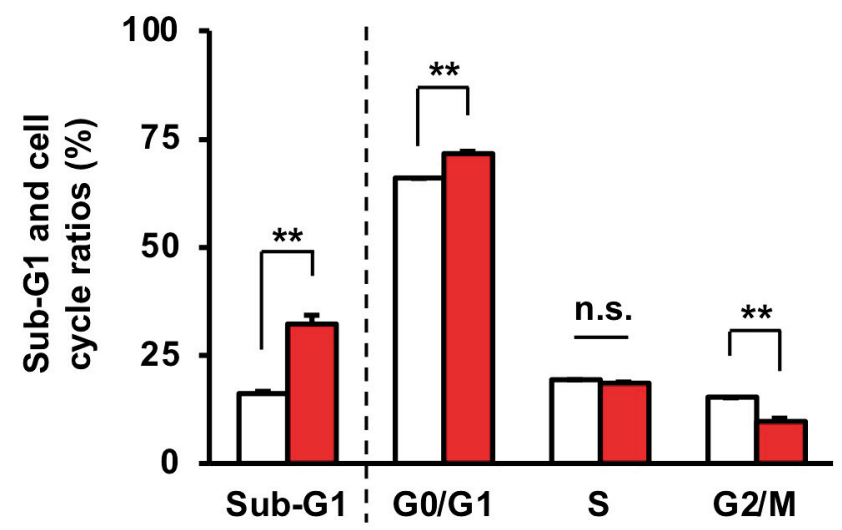

Figure 3. Effects of fucoxanthinol ( $\mathrm{FxOH}$ ) on apoptosis induction in pancreatic cancer HaPC-5 cells. HaPC-5 cells were treated with $5.0 \mu \mathrm{M}$ FxOH for 2 days. (A) Phase contrast microscopy images. Bar, $200 \mu \mathrm{m}$. (B) Proportion of sub-G $G_{1}$ phase (apoptotic-like cells) and cells in each cell-cycle phase $\left(G_{1}, S\right.$ and $\left.G_{2} / M\right)$ in $F x O H$-treated and control HaPC-5 cells, which were evaluated using a FACSAria-III flow cytometer are shown. Means \pm SE $(n=3)$. $* * p<0.01$.

(19 genes) were mainly correlated with many signals as follows: cell cycle, cell division, chemokine, cadherin, extracellular matrix, integrin, actin polymerization, microtubule organization, Ras, transforming growth factor beta (TGF- $\beta$ ) and wingless/integrated (Wnt). Moreover, a GO term for regulation of the MAPK cascade for biological processes was decreased by FxOH treatment (Figure 6, Tables III and IV). 


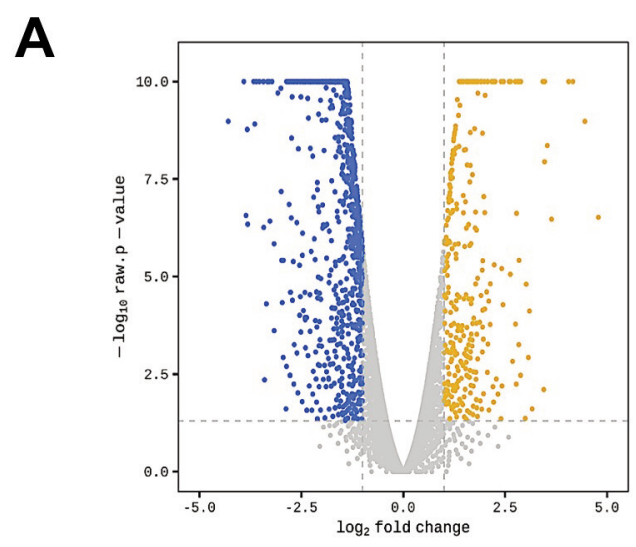

B
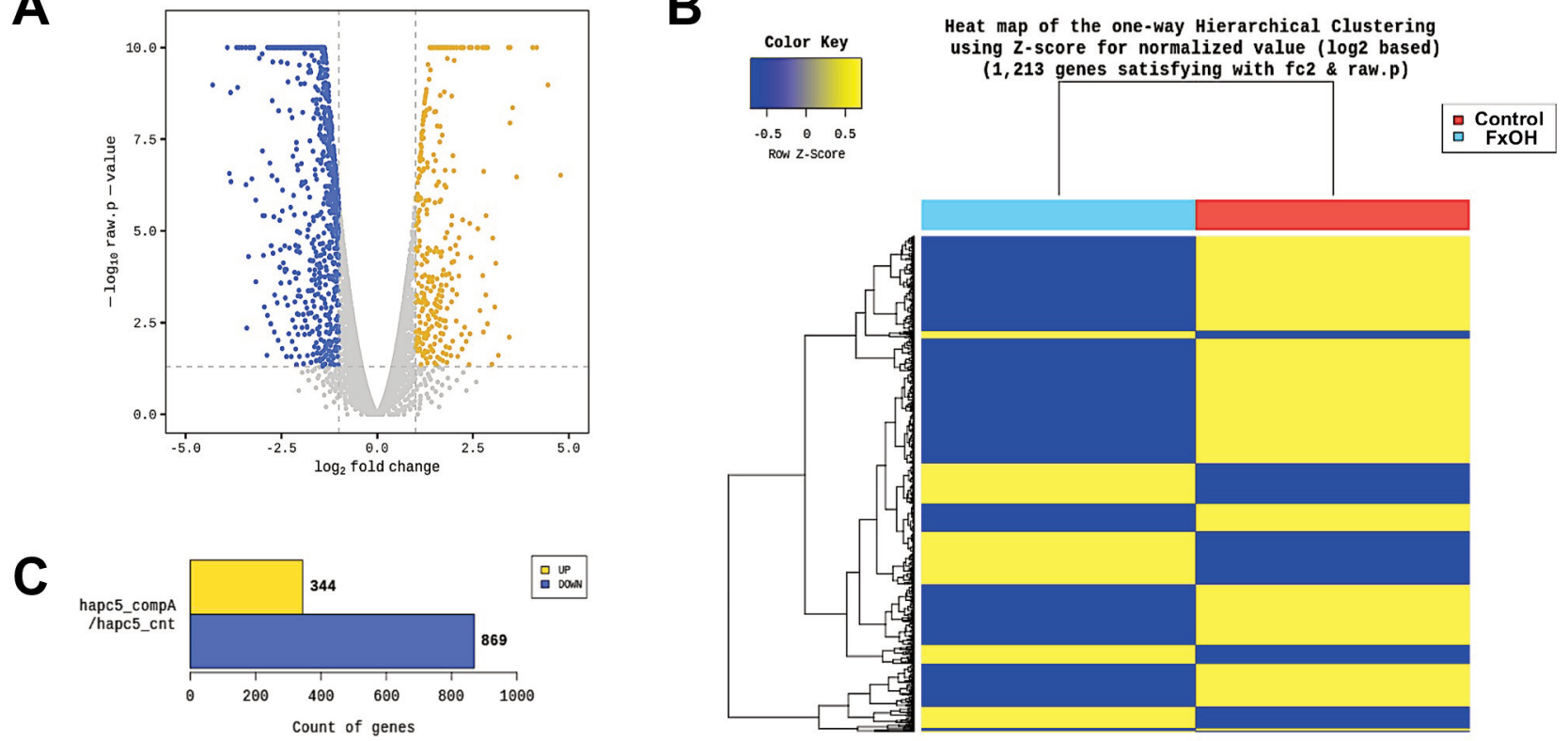

Figure 4. Effects of fucoxanthinol $(\mathrm{FxOH})$ on the transcriptome profile in $\mathrm{HaPC}-5$ cells. HaPC-5 cells were treated with $5.0 \mu \mathrm{M}$ FxOH for 1 day. Gene alterations between $\mathrm{FxOH}$-treated $\mathrm{HaPC}-5$ cells and control cells were analyzed using a next-generation sequencer NovaSeq 6000 system and sequencing control software (version 1.4.0). Levels of gene expression with $\geq 2.0$ and $\leq-2.0$-fold with cutoff p-value $<0.05$ in FxOH-treated HaPC-5 cells and control cells are presented as a sample with equivalently mixed mRNAs with triplicate experiments. (A) Volcano plots between the two groups. (B) Hierarchical clustering analysis for 1,213 genes with significant expression level differences between the two groups. (C) Number of up- ( $\geq 2.0$-fold $)$, and down-regulated ( $\leq-2.0$-fold) genes between the two groups. Yellow, up-regulated genes. Blue, down-regulated genes.

A

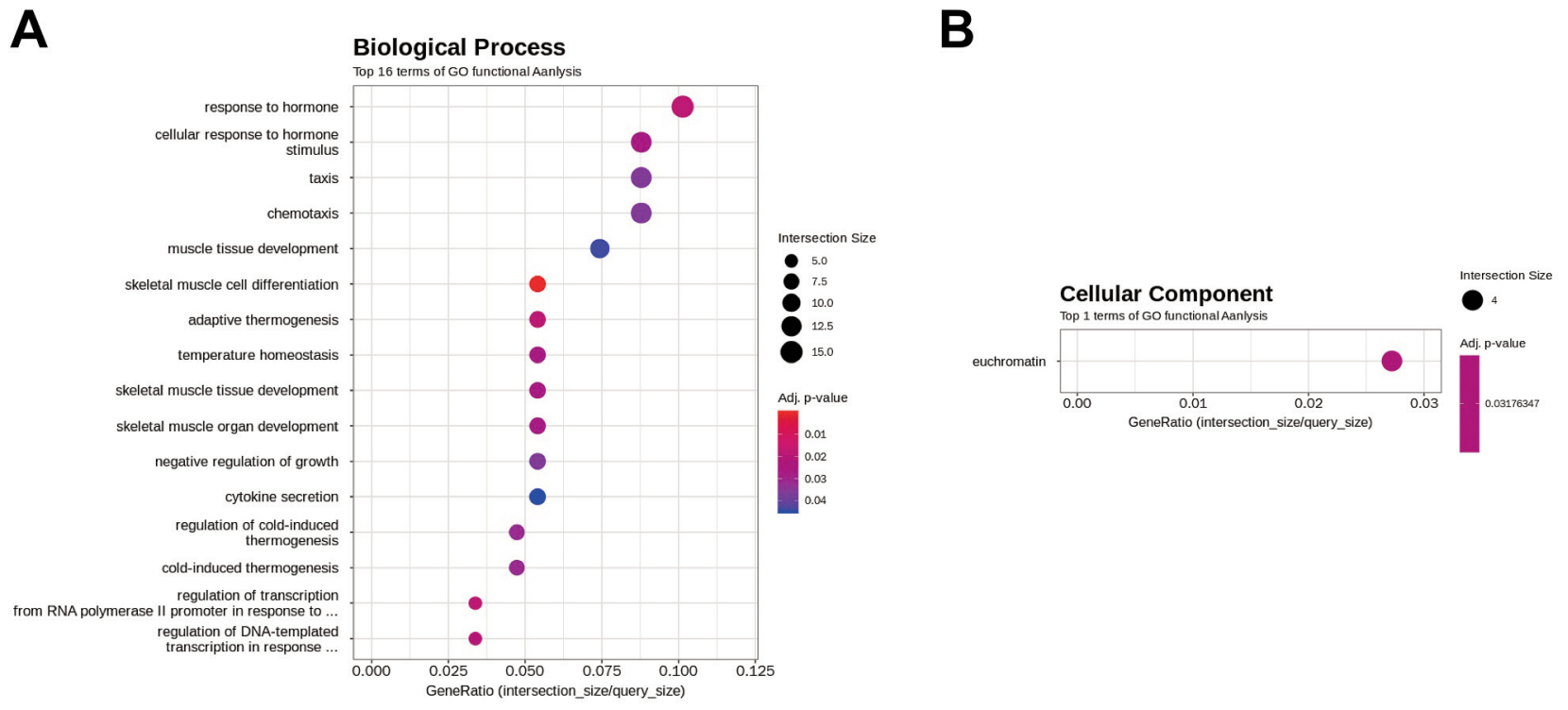

B

Figure 5. Gene ontology $(G O)$ enrichment profiles of genes up-regulated by fucoxanthinol (FxOH) treatment in HaPC-5 cells. The functional interpretation of genes up-regulated by $\geq 2.0$-fold and cutoff p-value $<0.05$ were performed using g:Profiler. The top 16 GO terms in more than four gene sizes are shown. (A) Sixteen GO terms in a biological process category. (B) One GO term in a cellular component category. 
Table II. Up-regulated genes in HaPC-5 cells treated with FxOH ${ }^{a}$.

\begin{tabular}{|c|c|c|c|}
\hline Gene symbol & Description & Fold ${ }^{b}$ & $p$-Value ${ }^{\mathrm{c}}$ \\
\hline \multicolumn{4}{|l|}{ Response to hormone } \\
\hline Prkcq & Protein kinase $\mathrm{C}$ theta & 8.6 & 0.001 \\
\hline Notch1 & Notch 1 & 7.4 & 0.026 \\
\hline $\operatorname{Socs} 2$ & Suppressor of cytokine signaling 2 & 5.3 & $<0.001$ \\
\hline Chrm1 & Cholinergic receptor muscarinic 1 & 5.0 & 0.061 \\
\hline Gdf15 & Growth differentiation factor 15 & 4.8 & $<0.001$ \\
\hline Ly6g6d & Lymphocyte antigen 6 family member G6D & 4.3 & 0.122 \\
\hline Slit3 & Slit guidance ligand 3 & 3.8 & $<0.001$ \\
\hline $\operatorname{Mef} 2 c$ & Myocyte enhancer factor $2 \mathrm{C}$ & 3.3 & 0.148 \\
\hline$N r 1 h 4$ & Nuclear receptor subfamily 1 group $\mathrm{H}$ member 4 & 3.1 & 0.011 \\
\hline Fibin & Fin bud initiation factor homolog (zebrafish) & 2.9 & 0.014 \\
\hline$N r 4 a 1$ & Nuclear receptor subfamily 4 group A member 1 & 2.8 & 0.016 \\
\hline Areg & Amphiregulin & 2.3 & 0.012 \\
\hline Rorb & RAR related orphan receptor B & 2.3 & $<0.001$ \\
\hline Sppl & Secreted phosphoprotein 1 & 2.1 & $<0.001$ \\
\hline Ddit4 & DNA damage inducible transcript 4 & 2.1 & $<0.001$ \\
\hline \multicolumn{4}{|c|}{ - } \\
\hline Hoxb9 & Homeobox B9 & 11.1 & $<0.001$ \\
\hline Prkcq & Protein kinase $\mathrm{C}$ theta & 8.6 & 0.001 \\
\hline Notch1 & Notch 1 & 7.4 & 0.026 \\
\hline LOC101840973 & Ephrin type-A receptor 7 & 4.2 & 0.022 \\
\hline $\operatorname{Tnfsf} 18$ & TNF superfamily member 18 & 4.1 & $<0.001$ \\
\hline Dysf & Dysferlin & 3.9 & $<0.001$ \\
\hline Slit3 & Slit guidance ligand 3 & 3.8 & $<0.001$ \\
\hline Ch25h & Cholesterol 25-hydroxylase & 3.3 & 0.104 \\
\hline LOC101827575 & $\mathrm{C}$-X-C motif chemokine 2-like & 3.1 & $<0.001$ \\
\hline$H s d 3 b 7$ & Hydroxy-delta-5-steroid dehydrogenase, 3 beta- and steroid delta-isomerase 7 & 2.4 & $<0.001$ \\
\hline Tbrl & T-box, brain 1 & 2.3 & 0.068 \\
\hline Ill7ra & Interleukin 17 receptor $\mathrm{A}$ & 2.3 & $<0.001$ \\
\hline$D c c$ & DCC netrin 1 receptor & 2.2 & 0.176 \\
\hline \multicolumn{4}{|c|}{ Muscle tissue development } \\
\hline Notch1 & Notch 1 & 7.4 & 0.026 \\
\hline LOC101840643 & Cytochrome P450 26B1 & 3.8 & $<0.001$ \\
\hline Mef $2 c$ & Myocyte enhancer factor $2 \mathrm{C}$ & 3.3 & 0.148 \\
\hline Nupr1 & Nuclear protein 1 , transcriptional regulator & 3.2 & $<0.001$ \\
\hline Nr4al & Nuclear receptor subfamily 4 group A member 1 & 2.8 & 0.016 \\
\hline Atf3 & Activating transcription factor 3 & 2.3 & $<0.001$ \\
\hline Ifrdl & Interferon related developmental regulator 1 & 2.3 & $<0.001$ \\
\hline Maff & MAF bZIP transcription factor $F$ & 2.3 & $<0.001$ \\
\hline Ppargcla & PPARG coactivator 1 alpha & 2.2 & 0.004 \\
\hline Ankrd2 & Ankyrin repeat domain 2 & 2.0 & 0.068 \\
\hline$K d m 6 b$ & Lysine demethylase 6B & 2.0 & $<0.001$ \\
\hline \multicolumn{4}{|l|}{ Euchromatin } \\
\hline Nrlh4 & Nuclear receptor subfamily 1 group $\mathrm{H}$ member 4 & 3.1 & 0.011 \\
\hline LOC101829141 & Histone H1.3 & 2.5 & 0.021 \\
\hline LOC101826763 & Histone H1.2 & 2.4 & 0.095 \\
\hline Ankrd2 & Ankyrin repeat domain 2 & 2.0 & 0.069 \\
\hline
\end{tabular}

HaPC, Hamster pancreatic cancer; FxOH, fucoxanthinol. aAmong all 1,213 genes significantly changed, up-regulated 43 genes classified to response to hormone, taxis, muscle tissue development and euchromatin in Gene Ontology (GO) term analysis are showed. ${ }^{b}$ Fold change of gene expression in FxOH-treated HaPC5 cells in comparison with that of control cells. ${ }^{\mathrm{c}}$ Significant difference between $\mathrm{HaPC} 5$ cells with and without FxOH treatments by an exact test on edgeR.

Effect of $\mathrm{FxOH}$ on Ackr3 (Cxcr7) gene expression in $\mathrm{HaPC}$ 5 cells. The gene expression of Ackr3 (Cxcr7) in HaPC-5 cells after $5.0 \mu \mathrm{M}$ FxOH treatment for 1 day was evaluated.
The mRNA expression of Ackr3 decreased significantly to 0.5 -fold after 5.0 $\mu \mathrm{M}$ FxOH treatment in HaPC-5 cells compared with untreated control cells (Figure 7). 

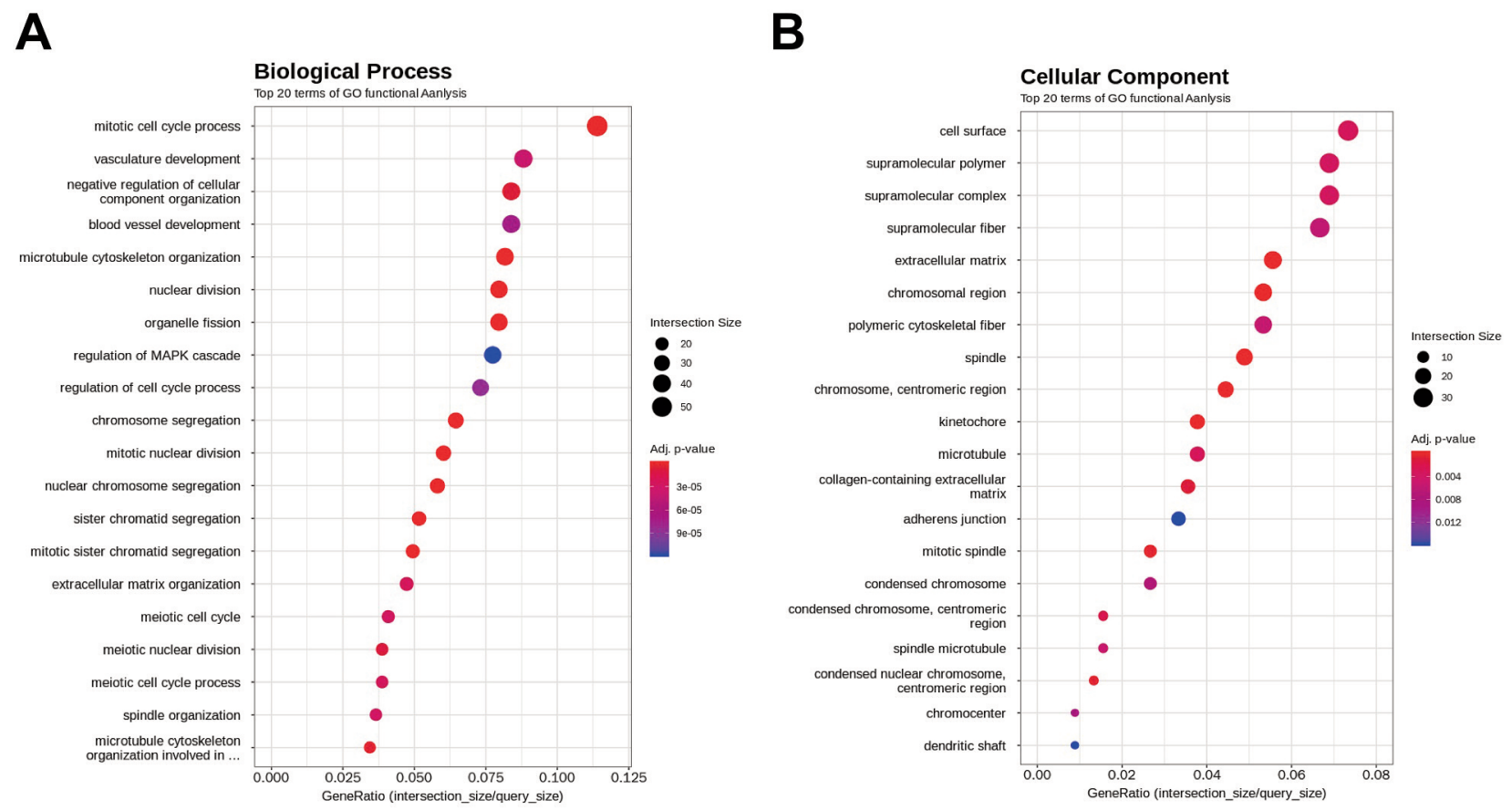

C

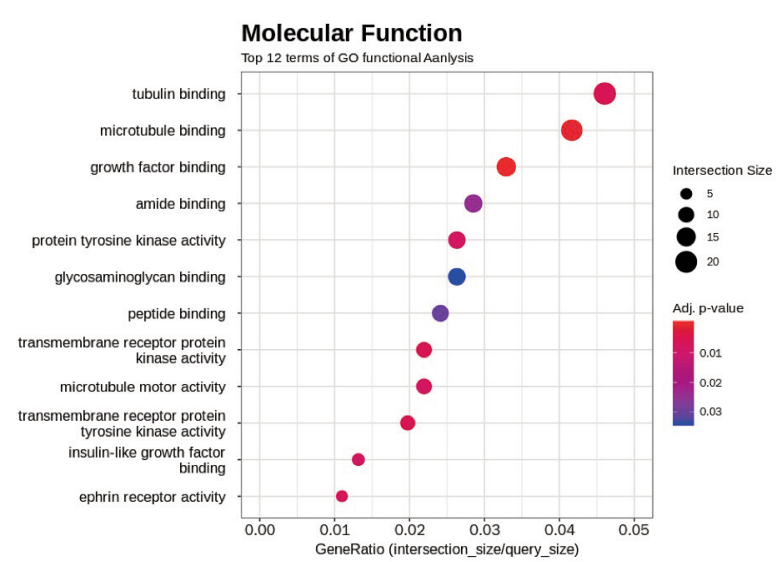

Figure 6. Gene ontology (GO) enrichment profiles of genes down-regulated by fucoxanthinol (FxOH) treatment in HaPC-5 cells. The functional interpretation of genes down-regulated by $\leq-2.0$-fold and cutoff p-value $<0.05$ were performed using g:Profiler. The top 20 GO terms in more than five gene sizes are shown. (A) Twenty GO terms in a biological process category. (B) Twenty GO terms in a cellular component category. (C) Twelve GO terms in a molecular function.

Effect of FxOH on protein expressions in $\mathrm{HaPC}-5$ cells. Based on the cell-cycle arrest and transcriptome analysis, the effect of $\mathrm{FxOH}$ on protein expression and activation in HaPC-5 cells was determined. FxOH treatment decreased the expression levels of cyclin D1, cyclin B1, CXCR7, integrin $\alpha 5, \operatorname{pFAK}\left(\mathrm{Tyr}^{397}\right)$, pPaxillin $\left(\operatorname{Tyr}^{31}\right)$, pAKT $\left(\operatorname{Ser}^{473}\right)$, and pSmad2 $\left(\operatorname{Ser}^{465 / 467}\right)$ and increased that of pERK1/2(Thr $\left.{ }^{202} / \mathrm{Tyr}^{204}\right)$ in HaPC-5 cells. Expression of cleaved caspase-3 (p17/p19), the active form of caspase-3, was increased in HaPC-5 cells after FxOH treatment.
Little difference between FxOH-treated HaPC-5 cells and control cells was observed for cyclin D2, CXCR4, integrin $\beta 1$, integrin $\beta 4$, integrin $\beta 8$, pAKT(Thy ${ }^{308}$ ), AKT(pan), pMEK1/2 $\left(\mathrm{Ser}^{217 / 221}\right)$, Smad2, pro-caspase-3, and p53 (Figure 8).

\section{Discussion}

The present study demonstrated that $\mathrm{FxOH}$ induced apoptosis in HaPC-5 cells through suppression of many 
Table III. Down-regulated genes in HaPC-5 cells treated with $\mathrm{FxOH}^{a}$.

\begin{tabular}{|c|c|c|c|}
\hline Gene symbol & Description & Fold $b$ & $p$-Value ${ }^{c}$ \\
\hline \multicolumn{4}{|c|}{$\begin{array}{l}\text { Biological process - } \\
\text { mitotic cell cycle process }\end{array}$} \\
\hline Edn1 & Endothelin 1 & -6.9 & $<0.001$ \\
\hline Dact1 & Dishevelled binding antagonist of beta catenin 1 & -4.5 & $<0.001$ \\
\hline Iqgap3 & IQ motif containing GTPase activating protein 3 & -3.9 & $<0.001$ \\
\hline Mastl & Microtubule associated serine/threonine kinase like & -3.6 & $<0.001$ \\
\hline$C d k n 2 c$ & Cyclin dependent kinase inhibitor $2 \mathrm{C}$ & -3.5 & $<0.001$ \\
\hline$A p c$ & APC, WNT signaling pathway regulator & -3.4 & $<0.001$ \\
\hline E2f7 & E2F transcription factor 7 & -3.4 & $<0.001$ \\
\hline Ccna2 & Cyclin A2 & -3.3 & $<0.001$ \\
\hline Nusap1 & Nucleolar and spindle associated protein 1 & -3.3 & $<0.001$ \\
\hline Cenpa & Centromere protein $\mathrm{A}$ & -3.0 & $<0.001$ \\
\hline Anln & Anillin actin binding protein & -2.9 & $<0.001$ \\
\hline Pkia & cAMP-dependent protein kinase inhibitor alpha & -2.9 & $<0.001$ \\
\hline Psrcl & Proline and serine rich coiled-coil 1 & -2.8 & 0.001 \\
\hline Fbxo5 & F-box protein 5 & -2.8 & $<0.001$ \\
\hline Aurkb & Aurora kinase B & -2.8 & $<0.001$ \\
\hline Chek2 & Checkpoint kinase 2 & -2.8 & $<0.001$ \\
\hline Ckap2 & Cytoskeleton associated protein 2 & -2.8 & $<0.001$ \\
\hline Bublb & BUB1 mitotic checkpoint serine/threonine kinase B & -2.8 & $<0.001$ \\
\hline Ect2 & Epithelial cell transforming 2 & -2.7 & $<0.001$ \\
\hline Espll & Extra spindle pole bodies like 1, separase & -2.7 & $<0.001$ \\
\hline Plk1 & Polo like kinase 1 & -2.7 & $<0.001$ \\
\hline Kif $2 c$ & Kinesin family member $2 \mathrm{C}$ & -2.7 & $<0.001$ \\
\hline Sapcd2 & Suppressor APC domain containing 2 & -2.6 & $<0.001$ \\
\hline Zwint & ZW10 interacting kinetochore protein & -2.5 & $<0.001$ \\
\hline Kif $20 b$ & Kinesin family member $20 \mathrm{~B}$ & -2.5 & $<0.001$ \\
\hline $\operatorname{Rad} 51 c$ & RAD51 paralog C & -2.5 & $<0.001$ \\
\hline$C d k 1$ & Cyclin dependent kinase 1 & -2.5 & $<0.001$ \\
\hline Knstrn & Kinetochore localized astrin/SPAG5 binding protein & -2.5 & $<0.001$ \\
\hline Foxm1 & Forkhead box M1 & -2.4 & $<0.001$ \\
\hline Trip13 & Thyroid hormone receptor interactor 13 & -2.4 & $<0.001$ \\
\hline Tacc3 & Transforming acidic coiled-coil containing protein 3 & -2.4 & $<0.001$ \\
\hline Sgol & Shugoshin 1 & -2.4 & $<0.001$ \\
\hline Spag 5 & Sperm associated antigen 5 & -2.3 & $<0.001$ \\
\hline Cdca8 & Cell division cycle associated 8 & -2.3 & $<0.001$ \\
\hline Cdc20 & Cell division cycle 20 & -2.3 & $<0.001$ \\
\hline$W d r 62$ & WD repeat domain 62 & -2.3 & $<0.001$ \\
\hline Gpnmb & Glycoprotein nmb & -2.3 & 0.063 \\
\hline Skp2 & S-phase kinase associated protein 2 & -2.3 & $<0.001$ \\
\hline Ccsap & Centriole, cilia and spindle associated protein & -2.2 & $<0.001$ \\
\hline$N d c 80$ & NDC80, kinetochore complex component & -2.2 & $<0.001$ \\
\hline Cdca5 & Cell division cycle associated 5 & -2.2 & $<0.001$ \\
\hline Pttg1 & Pituitary tumor-transforming 1 & -2.2 & $<0.001$ \\
\hline Smc4 & Structural maintenance of chromosomes 4 & -2.1 & $<0.001$ \\
\hline Mad2l1 & Mitotic arrest deficient 2 like 1 & -2.1 & $<0.001$ \\
\hline Kif20a & Kinesin family member $20 \mathrm{~A}$ & -2.1 & $<0.001$ \\
\hline Nek2 & NIMA related kinase 2 & -2.1 & $<0.001$ \\
\hline Ccne2 2 & Cyclin E2 & -2.1 & $<0.001$ \\
\hline Kif18a & Kinesin family member $18 \mathrm{~A}$ & -2.1 & $<0.001$ \\
\hline Ncapg & Non-SMC condensin I complex subunit G & -2.1 & $<0.001$ \\
\hline$C d k n 2 d$ & Cyclin dependent kinase inhibitor 2D & -2.1 & $<0.001$ \\
\hline Spry1 & Sprouty RTK signaling antagonist 1 & -2.1 & $<0.001$ \\
\hline Tpx2 & TPX2, microtubule nucleation factor & -2.0 & $<0.001$ \\
\hline Kif22 & Kinesin family member 22 & -2.0 & $<0.001$ \\
\hline \multicolumn{4}{|c|}{$\begin{array}{l}\text { Cellular component - } \\
\text { supramolecular polymer }\end{array}$} \\
\hline Collal & Collagen type I alpha 1 chain & -15.0 & $<0.001$ \\
\hline Thsd4 & Thrombospondin type 1 domain containing 4 & -11.5 & $<0.001$ \\
\hline Pgm5 & Phosphoglucomutase 5 & -8.4 & $<0.001$ \\
\hline
\end{tabular}


Table III. Continued

\begin{tabular}{|c|c|c|c|}
\hline Gene symbol & Description & Fold ${ }^{b}$ & $p$-Value $\mathrm{c}^{\mathrm{c}}$ \\
\hline$F k b p 1 b$ & FK506 binding protein $1 \mathrm{~B}$ & -6.7 & $<0.001$ \\
\hline Fbn1 & Fibrillin 1 & -3.4 & $<0.001$ \\
\hline Nusap1 & Nucleolar and spindle associated protein 1 & -3.3 & $<0.001$ \\
\hline Cryab & Crystallin alpha B & -3.2 & $<0.001$ \\
\hline Col4a6 & Collagen type IV alpha 6 chain & -3.2 & $<0.001$ \\
\hline Tubb3 & Tubulin beta 3 class III & -3.1 & $<0.001$ \\
\hline Psrcl & Proline and serine rich coiled-coil 1 & -2.8 & 0.001 \\
\hline Ckap2 & Cytoskeleton associated protein 2 & -2.8 & $<0.001$ \\
\hline Plk1 & Polo like kinase 1 & -2.7 & $<0.001$ \\
\hline Kif $2 c$ & Kinesin family member $2 \mathrm{C}$ & -2.7 & $<0.001$ \\
\hline$C d k 1$ & Cyclin dependent kinase 1 & -2.5 & $<0.001$ \\
\hline Gtse1 & G2 and S-phase expressed 1 & -2.5 & $<0.001$ \\
\hline Knstrn & Kinetochore localized astrin/SPAG5 binding protein & -2.5 & $<0.0017$ \\
\hline Rac3 & $\begin{array}{l}\text { Ras-related C3 botulinum toxin substrate } 3 \\
\text { (rho family, small GTP binding protein Rac3) }\end{array}$ & -2.5 & 0.070 \\
\hline$B f s p 2$ & Beaded filament structural protein 2 & -2.5 & $<0.001$ \\
\hline Lmnb1 & Lamin B1 & -2.4 & $<0.001$ \\
\hline Krt80 & Keratin 80 & -2.4 & 0.095 \\
\hline Synm & Synemin & -2.4 & $<0.001$ \\
\hline Spag5 & Sperm associated antigen 5 & -2.3 & $<0.001$ \\
\hline Tubel & Tubulin epsilon 1 & -2.2 & $<0.001$ \\
\hline Ccsap & Centriole, cilia and spindle associated protein & -2.2 & $<0.001$ \\
\hline Kifcl & Kinesin family member $\mathrm{C} 1$ & -2.2 & $<0.001$ \\
\hline Carmil1 & Capping protein regulator and myosin 1 linker 1 & -2.1 & $<0.001$ \\
\hline Kif20a & Kinesin family member $20 \mathrm{~A}$ & -2.1 & $<0.001$ \\
\hline Kif18a & Kinesin family member $18 \mathrm{~A}$ & -2.1 & $<0.001$ \\
\hline Tpx2 & TPX2, microtubule nucleation factor & -2.0 & $<0.001$ \\
\hline Krt 25 & Keratin 25 & -2.0 & $<0.001$ \\
\hline Kif 22 & Kinesin family member 22 & -2.0 & $<0.001$ \\
\hline \multicolumn{4}{|c|}{$\begin{array}{l}\text { Cellular component - } \\
\text { supramolecular complex }\end{array}$} \\
\hline Collal & Collagen type I alpha 1 chain & -15.0 & $<0.001$ \\
\hline Thsd4 & Thrombospondin type 1 domain containing 4 & -11.5 & $<0.001$ \\
\hline Pgm5 & Phosphoglucomutase 5 & -8.4 & $<0.001$ \\
\hline Fkbplb & FK506 binding protein $1 \mathrm{~B}$ & -6.7 & $<0.001$ \\
\hline Fbn1 & Fibrillin 1 & -3.4 & $<0.001$ \\
\hline Nusap1 & Nucleolar and spindle associated protein 1 & -3.3 & $<0.001$ \\
\hline Cryab & Crystallin alpha B & -3.2 & $<0.001$ \\
\hline Col4a6 & Collagen type IV alpha 6 chain & -3.2 & $<0.001$ \\
\hline Tubb3 & Tubulin beta 3 class III & -3.1 & $<0.001$ \\
\hline Psrcl & Proline and serine rich coiled-coil 1 & -2.8 & $<0.001$ \\
\hline Ckap2 & Cytoskeleton associated protein 2 & -2.8 & $<0.001$ \\
\hline Plk1 & Polo like kinase 1 & -2.7 & $<0.001$ \\
\hline Kif $2 c$ & Kinesin family member $2 \mathrm{C}$ & -2.7 & $<0.001$ \\
\hline$C d k 1$ & Cyclin dependent kinase 1 & -2.5 & $<0.001$ \\
\hline Gtse1 & G2 and S-phase expressed 1 & -2.5 & $<0.001$ \\
\hline Knstrn & Kinetochore localized astrin/SPAG5 binding protein & -2.5 & $<0.001$ \\
\hline Rac3 & $\begin{array}{l}\text { Ras-related C3 botulinum toxin substrate } 3 \\
\text { (rho family, small GTP binding protein Rac3) }\end{array}$ & -2.5 & 0.070 \\
\hline Bfsp2 & Beaded filament structural protein 2 & -2.5 & $<0.001$ \\
\hline Lmnb1 & Lamin B1 & -2.4 & $<0.001$ \\
\hline Krt80 & Keratin 80 & -2.4 & 0.095 \\
\hline Synm & Synemin & -2.4 & $<0.001$ \\
\hline Spag5 & Sperm associated antigen 5 & -2.3 & $<0.001$ \\
\hline Tubel & Tubulin epsilon 1 & -2.2 & $<0.001$ \\
\hline Ccsap & Centriole, cilia and spindle associated protein & -2.2 & $<0.001$ \\
\hline Kifcl & Kinesin family member $\mathrm{C} 1$ & -2.2 & $<0.001$ \\
\hline Carmil1 & Capping protein regulator and myosin 1 linker 1 & -2.1 & $<0.001$ \\
\hline Kif20a & Kinesin family member $20 \mathrm{~A}$ & -2.1 & $<0.001$ \\
\hline Kifl $18 a$ & Kinesin family member $18 \mathrm{~A}$ & -2.1 & $<0.001$ \\
\hline
\end{tabular}


Table III. Continued

\begin{tabular}{|c|c|c|c|}
\hline Gene symbol & Description & Fold $b$ & $p$-Value ${ }^{\mathrm{c}}$ \\
\hline $\operatorname{Tp} x 2$ & TPX2, microtubule nucleation factor & -2.0 & $<0.001$ \\
\hline Krt 25 & Keratin 25 & -2.0 & $<0.001$ \\
\hline Kif 22 & Kinesin family member 22 & -2.0 & $<0.001$ \\
\hline \multicolumn{4}{|c|}{$\begin{array}{l}\text { Cellular component - } \\
\text { supramolecular fiber }\end{array}$} \\
\hline Collal & Collagen type I alpha 1 chain & -15.0 & $<0.001$ \\
\hline Thsd4 & Thrombospondin type 1 domain containing 4 & -11.5 & $<0.001$ \\
\hline Sorbs 2 & Sorbin and SH3 domain containing 2 & -10.0 & $<0.001$ \\
\hline$E d n 1$ & Endothelin 1 & -6.9 & $<0.001$ \\
\hline Adamts 14 & ADAM metallopeptidase with thrombospondin type 1 motif 14 & -5.5 & $<0.001$ \\
\hline Wnt4 & Wnt family member 4 & -4.8 & $<0.001$ \\
\hline$C d h 5$ & Cadherin 5 & -4.1 & $<0.001$ \\
\hline Apc & APC, WNT signaling pathway regulator & -3.4 & $<0.001$ \\
\hline Ltbp 2 & Latent transforming growth factor beta binding protein 2 & -3.3 & $<0.001$ \\
\hline Cryab & Crystallin alpha B & -3.2 & $<0.001$ \\
\hline Ctgf & Connective tissue growth factor & -3.1 & $<0.001$ \\
\hline$T g f b 2$ & Transforming growth factor beta 2 & -3.1 & $<0.001$ \\
\hline Efemp2 & EGF containing fibulin like extracellular matrix protein 2 & -3.0 & 0.001 \\
\hline Psrcl & Proline and serine rich coiled-coil 1 & -2.8 & 0.001 \\
\hline Fbxo5 & F-box protein 5 & -2.8 & $<0.001$ \\
\hline Ckap2 & Cytoskeleton associated protein 2 & -2.8 & $<0.001$ \\
\hline Ptger4 & Prostaglandin E receptor 4 & -2.7 & $<0.001$ \\
\hline Kif $2 c$ & Kinesin family member $2 \mathrm{C}$ & -2.7 & $<0.001$ \\
\hline Pdgfra & Platelet derived growth factor receptor alpha & -2.6 & $<0.001$ \\
\hline Phldb2 & Pleckstrin homology like domain family B member 2 & -2.6 & $<0.001$ \\
\hline$C d c 42 e p 2$ & CDC42 effector protein 2 & -2.5 & $<0.001$ \\
\hline$L d l r$ & Low density lipoprotein receptor & -2.5 & $<0.001$ \\
\hline$P d e 2 a$ & Phosphodiesterase 2A & -2.4 & $<0.001$ \\
\hline Loxl3 & Lysyl oxidase like 3 & -2.3 & $<0.001$ \\
\hline Kiaa1211 & KIAA1211 ortholog & -2.2 & $<0.001$ \\
\hline Coro $2 b$ & Coronin $2 \mathrm{~B}$ & -2.2 & $<0.001$ \\
\hline Ccsap & Centriole, cilia and spindle associated protein & -2.2 & $<0.001$ \\
\hline P3h4 & Prolyl 3-hydroxylase family member 4 (non-enzymatic) & -2.2 & $<0.001$ \\
\hline Carmil1 & Capping protein regulator and myosin 1 linker 1 & -2.1 & $<0.001$ \\
\hline Kif18a & Kinesin family member $18 \mathrm{~A}$ & -2.1 & $<0.001$ \\
\hline LOC101839568 & Cytochrome P450 1B1 & -2.1 & 0.039 \\
\hline Krt25 & Keratin 25 & -2.0 & $<0.001$ \\
\hline Kif 24 & Kinesin family member 24 & -2.0 & $<0.001$ \\
\hline \multicolumn{4}{|c|}{ Molecular function - tubulin binding } \\
\hline Kif $26 a$ & Kinesin family member $26 \mathrm{~A}$ & -5.7 & $<0.001$ \\
\hline Gas2 & Growth arrest specific 2 & -3.6 & 0.031 \\
\hline Nusap1 & Nucleolar and spindle associated protein 1 & -3.3 & $<0.001$ \\
\hline Cep70 & Centrosomal protein 70 & -3.0 & $<0.001$ \\
\hline Psrcl & Proline and serine rich coiled-coil 1 & -2.8 & 0.001 \\
\hline Prcl & Protein regulator of cytokinesis 1 & -2.8 & $<0.001$ \\
\hline Plk1 & Polo like kinase 1 & -2.7 & $<0.001$ \\
\hline Kif $2 c$ & Kinesin family member $2 \mathrm{C}$ & -2.7 & $<0.001$ \\
\hline Kif $20 b$ & Kinesin family member $20 \mathrm{~B}$ & -2.5 & $<0.001$ \\
\hline Kif15 & Kinesin family member 15 & -2.4 & $<0.001$ \\
\hline$P d e 4 b$ & Phosphodiesterase 4B & -2.4 & $<0.001$ \\
\hline Spag 5 & Sperm associated antigen 5 & -2.3 & $<0.001$ \\
\hline$M d m 1$ & Mdm1 nuclear protein & -2.3 & $<0.001$ \\
\hline Ccsap & Centriole, cilia and spindle associated protein & -2.2 & $<0.001$ \\
\hline Kifl $18 b$ & Kinesin family member $18 \mathrm{~B}$ & -2.2 & $<0.001$ \\
\hline Kifc1 & Kinesin family member $\mathrm{C} 1$ & -2.2 & $<0.001$ \\
\hline Kif $20 a$ & Kinesin family member $20 \mathrm{~A}$ & -2.1 & $<0.001$ \\
\hline Kifl $18 a$ & Kinesin family member $18 \mathrm{~A}$ & -2.1 & $<0.001$ \\
\hline Dpysl2 & Dihydropyrimidinase like 2 & -2.0 & $<0.001$ \\
\hline Kif 24 & Kinesin family member 24 & -2.0 & $<0.001$ \\
\hline Kif 22 & Kinesin family member 22 & -2.0 & $<0.001$ \\
\hline
\end{tabular}


Table III. Continued

\begin{tabular}{|c|c|c|c|}
\hline Gene symbol & Description & Fold ${ }^{b}$ & $p$-Value ${ }^{\mathrm{c}}$ \\
\hline \multicolumn{4}{|c|}{$\begin{array}{l}\text { Molecular function - } \\
\text { microtubule binding }\end{array}$} \\
\hline Kif26a & Kinesin family member $26 \mathrm{~A}$ & -5.7 & $<0.001$ \\
\hline Gas2 & Growth arrest specific 2 & -3.6 & 0.031 \\
\hline Nusapl & Nucleolar and spindle associated protein 1 & -3.3 & $<0.001$ \\
\hline Psrcl & Proline and serine rich coiled-coil 1 & -2.8 & 0.001 \\
\hline $\operatorname{Prcl}$ & Protein regulator of cytokinesis 1 & -2.8 & $<0.001$ \\
\hline Plkl & Polo like kinase 1 & -2.7 & $<0.001$ \\
\hline$K i f 2 c$ & Kinesin family member $2 \mathrm{C}$ & -2.7 & $<0.001$ \\
\hline Kif $20 b$ & Kinesin family member $20 \mathrm{~B}$ & -2.5 & $<0.001$ \\
\hline Kif15 & Kinesin family member 15 & -2.4 & $<0.001$ \\
\hline Spag5 & Sperm associated antigen 5 & -2.3 & $<0.001$ \\
\hline$M d m 1$ & Mdm1 nuclear protein & -2.3 & $<0.001$ \\
\hline Ccsap & Centriole, cilia and spindle associated protein & -2.2 & $<0.001$ \\
\hline Kif18b & Kinesin family member $18 \mathrm{~B}$ & -2.2 & $<0.001$ \\
\hline Kifcl & Kinesin family member $\mathrm{C} 1$ & -2.2 & $<0.001$ \\
\hline Kif $20 a$ & Kinesin family member $20 \mathrm{~A}$ & -2.1 & $<0.001$ \\
\hline Kif18a & Kinesin family member $18 \mathrm{~A}$ & -2.1 & $<0.001$ \\
\hline Dpysl2 & Dihydropyrimidinase like 2 & -2.0 & $<0.001$ \\
\hline Kif 24 & Kinesin family member 24 & -2.0 & $<0.001$ \\
\hline Kif22 & Kinesin family member 22 & -2.0 & $<0.001$ \\
\hline
\end{tabular}

HaPC, Hamster pancreatic cancer; FxOH, fucoxanthinol. aAmong all 1,213 genes significantly changed, down-regulated genes classified to biological process [1 gene ontology (GO) term], cellular component (3 GO terms) and molecular function (2 GO terms) in GO term analysis are showed. bFold change of gene expression in FxOH-treated HaPC5 cells in comparison with that of control cells. ${ }^{c}$ Significant difference between HaPC5 cells with and without FxOH treatments by an exact test on edgeR.

genes and signal transduction pathways. This is the first study suggesting the anti-proliferating effect of $\mathrm{FxOH}$ on cell lines from a hamster pancreatic cancer model.

No associations between pathological findings and growth inhibition in FxOH-treated HaPC-1-6 were observed (Table I and Figure 2). However, FxOH significantly suppressed the growth of HaPC-1, $-4,-5$, and -6 cells among the six types of HaPC cells (Figure 2). Thus, we decided to elucidate the molecular mechanisms of the growth inhibitory effects using FxOH-treated HaPC-5 cells, which showed the highest growth inhibition. For example, 5.0 $\mu \mathrm{M}$ FxOH treatment significantly induced apoptosis in HaPC-5 cells with $\mathrm{G}_{1}$ phase arrest (Figure 3B).

Transcriptome analysis revealed that $\mathrm{FxOH}$ treatment significantly inhibited gene sets for cell cycle, cell division, chemokine, cadherin, extracellular matrix, integrin, actin polymerization, microtubule organization, and the pathways of the renin-angiotensin system, MAPK, TGF- $\beta$, and Wnt in HaPC-5 cells (Figure 6, Tables III and IV). On the other hand, few up-regulated genes involved in apoptosis induction were found (Figure 5 and Table II). Based on these transcriptome profiles, we confirmed alterations in the levels of proteins related to cell cycle, chemokines, adhesion, apoptosis, and pathways for PI3K/AKT, MAPK, and TGF- $\beta$ by western blotting analysis. Western blotting analysis showed that the levels of cyclin D1, cyclin B1, CXCR7, integrin $\alpha 5$,
pFAK $\left(\operatorname{Tyr}^{397}\right)$, pPaxillin $\left(\operatorname{Tyr}^{31}\right)$, pAKT $\left(\operatorname{Ser}^{473}\right)$, and pSmad2 $\left(\mathrm{Ser}^{465 / 467}\right)$ were decreased, and pERK1/2(Thr $\left.{ }^{202} / \mathrm{Tyr}^{204}\right)$ and cleaved caspase-3(p17/p19) levels were increased in FxOHtreated HaPC-5 cells (Figure 8).

In the present study, $\mathrm{FxOH}$ treatment inhibited the cell cycle in HaPC-5 cells (Figures 3B and 8). The effects of cell cycle arrest by $\mathrm{FxOH}$ or $\mathrm{Fx}$ in cancer cells were previously found in various cancer cell lines $(20,28,29)$. As was observed in pancreatic cancer cells, cell-cycle arrest followed by apoptosis induction may be a common feature of various cancer cells.

In the present experiments, we especially focused on the expression levels of CXC motif chemokine receptor 4 (Cxcr4) and atypical chemokine receptor 3 (Ackr3, also called as $C x c r 7$ ) with the GO term for cell surface in cellular component. Regarding CXCR7, a significant decrease in Ackr3 (Cxcr7) gene expression was also identified (Figure 7). FxOH treatment also decreased CXCR7 expression but not CXCR4 in HaPC-5 cells (Figure 8). CXCR7, a member of the chemokine receptors, is known to interact with homeostatic and inflammatory chemokines, although CXCR4 interacts only with homeostatic chemokines (30). CXCR7 has been reported to enhance cell growth, migration and metastasis, induction of angiogenesis, homing of immune cells, recruitment of $\beta$-arrestin, release of interleukin, and activation of the vascular endothelial growth 
Table IV. Down-regulated genes in HaPC-5 cells treated with $\mathrm{FxOH}^{a}$.

\begin{tabular}{|c|c|c|c|}
\hline Gene symbol & Description & Fold ${ }^{b}$ & $p$-Value ${ }^{c}$ \\
\hline \multicolumn{4}{|c|}{$\begin{array}{l}\text { Cellular component - } \\
\text { cell surface }\end{array}$} \\
\hline Lipg & Lipase G, endothelial type & -12.7 & $<0.001$ \\
\hline Fut4 & Fucosyltransferase 4 & -10.3 & $<0.001$ \\
\hline Anpep & Alanyl aminopeptidase, membrane & -9.0 & 0.003 \\
\hline$L b p$ & Lipopolysaccharide binding protein & -7.0 & $<0.001$ \\
\hline $\operatorname{Itg} b 8$ & Integrin subunit beta 8 & -5.8 & $<0.001$ \\
\hline Folhlb & Folate hydrolase 1B & -5.0 & $<0.001$ \\
\hline Adamts9 & ADAM metallopeptidase with thrombospondin type 1 motif 9 & -4.9 & 0.003 \\
\hline Bgn & Biglycan & -4.2 & $<0.001$ \\
\hline$C d h 5$ & Cadherin 5 & -4.1 & $<0.001$ \\
\hline Mxra8 & Matrix remodeling associated 8 & -3.7 & $<0.001$ \\
\hline Cxcr4 & $\mathrm{C}-\mathrm{X}-\mathrm{C}$ motif chemokine receptor 4 & -3.5 & $<0.001$ \\
\hline$A b c c 2$ & ATP binding cassette subfamily $\mathrm{C}$ member 2 & -3.5 & $<0.001$ \\
\hline Pcsk6 & Proprotein convertase subtilisin/kexin type 6 & -3.4 & $<0.001$ \\
\hline Adamts 7 & ADAM metallopeptidase with thrombospondin type 1 motif 7 & -3.3 & $<0.001$ \\
\hline Ephb6 & $\mathrm{EPH}$ receptor B6 & -3.2 & $<0.001$ \\
\hline Aqp11 & Aquaporin 11 & -3.2 & $<0.001$ \\
\hline Sulf2 & Sulfatase 2 & -3.2 & $<0.001$ \\
\hline Gpc4 & Glypican 4 & -2.7 & $<0.001$ \\
\hline $\operatorname{Itg} b 4$ & Integrin subunit beta 4 & -2.7 & $<0.001$ \\
\hline Pdgfra & Platelet derived growth factor receptor alpha & -2.6 & $<0.001$ \\
\hline Efna5 & Ephrin A5 & -2.6 & $<0.001$ \\
\hline$R t n 4 r$ & Reticulon 4 receptor & -2.6 & $<0.001$ \\
\hline$L d l r$ & Low density lipoprotein receptor & -2.5 & $<0.001$ \\
\hline Ptprj & Protein tyrosine phosphatase, receptor type J & -2.3 & $<0.001$ \\
\hline Vasn & Vasorin & -2.3 & $<0.001$ \\
\hline Rgma & Repulsive guidance molecule family member a & -2.2 & $<0.001$ \\
\hline Ackr3 & Atypical chemokine receptor 3 & -2.1 & $<0.001$ \\
\hline Sparc & Secreted protein acidic and cysteine rich & -2.1 & $<0.001$ \\
\hline Csflr & Colony stimulating factor 1 receptor & -2.0 & $<0.001$ \\
\hline Ramp2 & Receptor activity modifying protein 2 & -2.0 & 0.017 \\
\hline Rtn 4 rll & Reticulon 4 receptor like 1 & -2.0 & $<0.001$ \\
\hline
\end{tabular}

HaPC, Hamster pancreatic cancer; FxOH, fucoxanthinol. aAmong 1,213 genes with significantly changed in expression levels, 32 down-regulated genes classified as cell surface among cellular components in the gene ontology term analysis are shown. ${ }^{b}$ Fold change in gene expression in FxOHtreated HaPC-5 cells in comparison with that of control cells. 'Significant difference between HaPC-5 cells with and without FxOH treatments using an exact test in edgeR.

factor, PI3K/AKT, mammalian target or rapamycin, and MAPK pathways $(31,32)$. CXCR7 is highly expressed in both pancreatic cancer tissue and pancreatic cancer cell lines (33). This protein expression is positively associated with poor prognosis in pancreatic cancer patients $(32,34-36)$.

FxOH treatment also decreased the expression of integrin $\alpha 5$, and the activation of FAK and Paxillin, which are downstream regulators of integrins, in HaPC-5 cells (Figure 8). Anoikis is caspase-dependent apoptosis that happens after the detachment of cancer cells from the extracellular matrix via attenuation of integrin signaling along with the suppression of PI3K/AKT, MAPK, and TGF- $\beta$ signals (3739). Our previous studies demonstrated that $\mathrm{Fx}$ and $\mathrm{FxOH}$ induce anoikis in murine colorectal tissue and in colon cancer DLD-1 cells, respectively, through suppression of

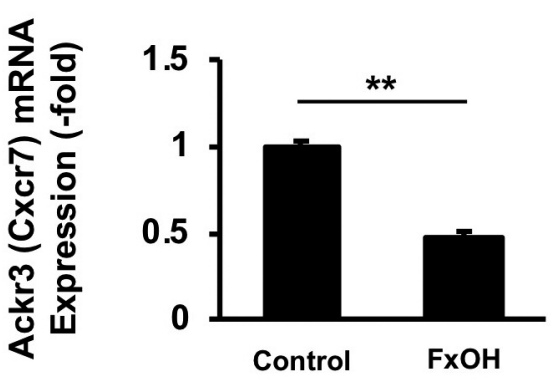

Figure 7. Effect of fucoxanthinol $(\mathrm{FxOH})$ on Ackr3 gene expression in $\mathrm{HaPC}-5$ cells. $\mathrm{HaPC}-5$ cells were treated with $5.0 \mu \mathrm{M}$ FxOH for 1 day. Ackr3 mRNA expression was determined using quantitative PCR. Expression was normalized to Gapdh expression levels. Ackr3 mRNA expression in the control cells was set as 1.0. Means \pm SE $(n=3)$. $* * p<0.01$. 

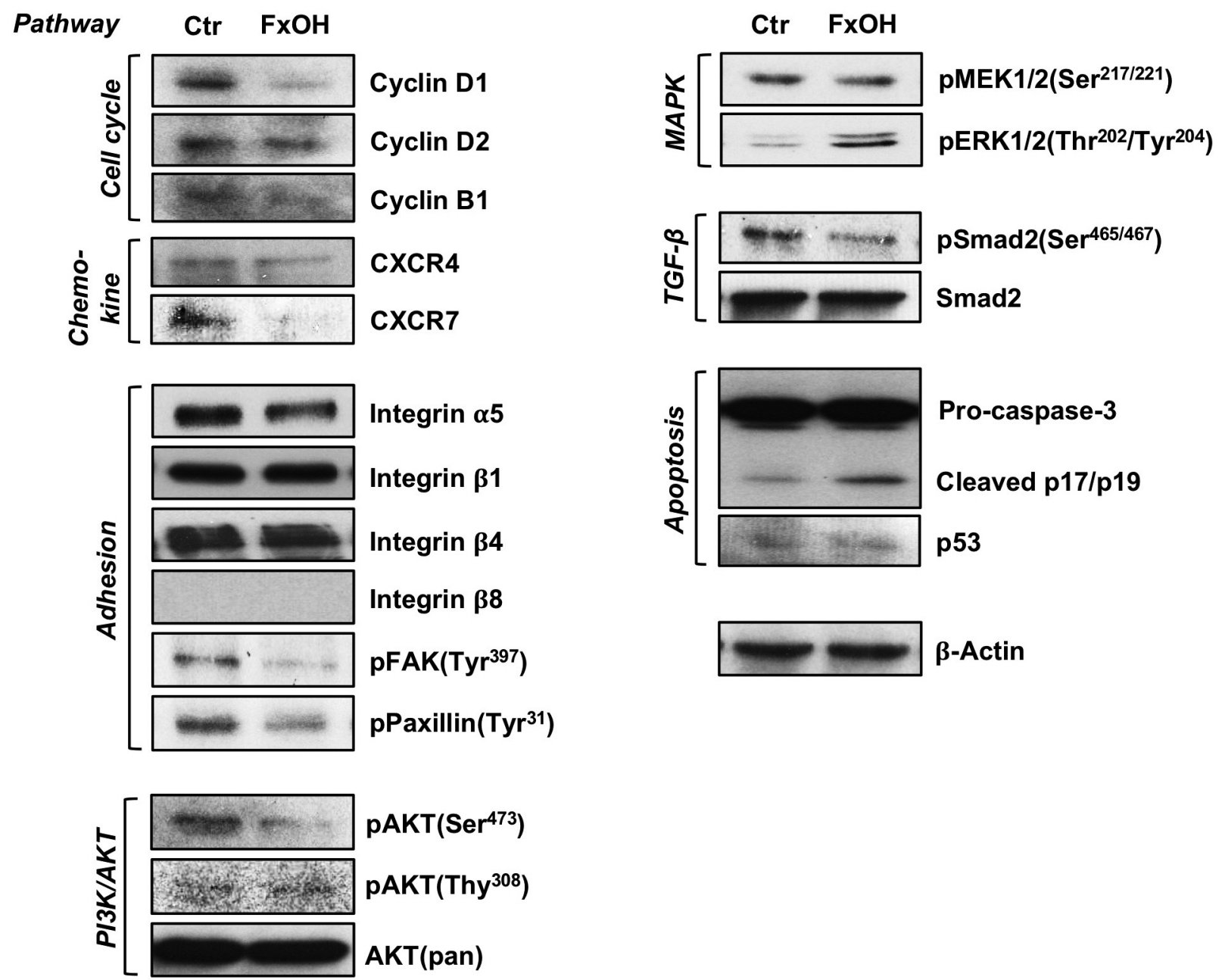

Figure 8. Effect of fucoxanthinol $(\mathrm{FxOH})$ on protein expression levels in $\mathrm{HaPC}-5$ cells. HaPC5 cells were treated with $5.0 \mu \mathrm{M} \mathrm{FxOH} \mathrm{for} 1$ day, and protein expression levels were evaluated using western blotting. Levels of indicated protein are shown with $\beta$-actin (internal control).

integrin signals $(25,26)$. FxOH is also known to downregulate many cytoskeletal genes in $\mathrm{HaPC}-5$ cells (Figure 6, Tables III and IV). Taking into consideration that integrins interact with the extracellular matrix and intracellular cytoskeleton, and promote migration/metastasis in cancer cells (40-42), it was suggested that FxOH may suppress firstly CXCR7 and integrin $\alpha 5$ on cellular membrane, and then alter the down-streams of PI3K/AKT, FAK/Paxillin, TGF- $\beta$ and cell cycle signals, actin polymerization and microtubule organization in HaPC-5 cells, followed by apoptosis and anoikis inductions.

A previous study revealed the growth inhibition by Fx in a human pancreatic cancer MIA PaCa-2 cell (43). On the other hands, crocetinic acid, a carotenoid having two carboxylic acids, induced apoptosis in human pancreatic cancer MIA PaCa-2 cells and suppressed a tumorigenesis in the xenograft model mice by inhibiting EGFR and AKT pathways (44). Lycopene, a hydrophobic carotenoid, could induce apoptosis in human pancreatic cancer PANC-1 cells by inhibiting the activation of NF-kB signals through suppression of reactive oxygen species (45). Further studies are needed to elucidate the effects of $\mathrm{FxOH}$ in pancreatic cancer cells.

In conclusion, FxOH modified the expression levels of 1,213 genes and induced apoptosis in a pancreatic ductal adenocarcinoma HaPC-5 cell cloned from a pancreatic cancer hamster model. Moreover, the protein expression and activation levels of cyclin D1, cyclin B1, CXCR7, integrin $\alpha 5, \operatorname{pFAK}\left(\mathrm{Tyr}^{397}\right), \operatorname{pPaxillin}\left(\mathrm{Tyr}^{31}\right), \operatorname{pAKT}\left(\mathrm{Ser}^{473}\right)$, and pSmad2(Ser $\left.{ }^{465 / 467}\right)$, which play central roles in cell cycle, chemokine, adhesion, and TGF- $\beta$ signals were significantly suppressed. Our findings suggested that $\mathrm{FxOH}$ may have 
high potential as a cancer chemopreventive agent in a hamster pancreatic carcinogenesis model.

\section{Conflicts of Interest}

No conflicts of interest.

\section{Authors' Contributions}

M. Terasaki conceived and designed the study and wrote the paper. M. Terasaki, Y.N., W. M., T. T. and M. Takahashi performed the experiments. A. K., H. K., M. K., H. M., K. M., M. M. and M. Takahashi reviewed and edited the manuscript. All Authors read and approved the final manuscript.

\section{Acknowledgements}

This work was supported in part by the Japan Society for the Promotion of Science KAKENHI (Grant Number 20K05879, 19H05652 and 19K07150).

\section{References}

1 Ferlay J, Colombet M, Soerjomataram I, Mathers C, Parkin DM, Piñeros M, Znaor A and Bray F: Estimating the global cancer incidence and mortality in 2018: GLOBOCAN sources and methods. Int J Cancer 144(8): 1941-1953, 2019. PMID: 30350310. DOI: $10.1002 / \mathrm{ijc} .31937$

2 American Cancer Society: Cancer Facts and Figures 2020. American Cancer Society, Atlanta, GA USA. Available at: https://www.cancer.org/research/cancer-facts-statistics/all-cancerfacts-figures/cancer-facts-figures-2020 html [Last accessed on February 12, 2021]

3 Puleo F, Nicolle R, Blum Y, Cros J, Marisa L, Demetter P, Quertinmont E, Svrcek M, Elarouci N, Iovanna J, Franchimont $\mathrm{D}$, Verset L, Galdon MG, Devière J, de Reyniès A, Laurent-Puig P, Van Laethem JL, Bachet JB and Maréchal R: Stratification of pancreatic ductal adenocarcinomas based on tumor and microenvironment features. Gastroenterology 155(6): 19992013.e3, 2018. PMID: 30165049. DOI: 10.1053/j.gastro.2018. 08.033

4 Cancer Genome Atlas Research Network. Electronic address: andrew_aguirre@dfci.harvard.edu. and Cancer Genome Atlas Research Network.: Integrated Genomic Characterization of Pancreatic Ductal Adenocarcinoma. Cancer Cell 32(2): 185203.e13, 2017. PMID: 28810144. DOI: 10.1016/j.ccell.2017. 07.007

5 Bailey P, Chang DK, Nones K, Johns AL, Patch AM, Gingras MC, Miller DK, Christ AN, Bruxner TJ, Quinn MC, Nourse C, Murtaugh LC, Harliwong I, Idrisoglu S, Manning S, Nourbakhsh E, Wani S, Fink L, Holmes O, Chin V, Anderson MJ, Kazakoff S, Leonard C, Newell F, Waddell N, Wood S, Xu Q, Wilson PJ, Cloonan N, Kassahn KS, Taylor D, Quek K, Robertson A, Pantano L, Mincarelli L, Sanchez LN, Evers L, Wu J, Pinese M, Cowley MJ, Jones MD, Colvin EK, Nagrial AM, Humphrey ES, Chantrill LA, Mawson A, Humphris J, Chou A, Pajic M, Scarlett CJ, Pinho AV, Giry-Laterriere M, Rooman I, Samra JS, Kench JG, Lovell JA, Merrett ND, Toon CW, Epari K, Nguyen NQ,
Barbour A, Zeps N, Moran-Jones K, Jamieson NB, Graham JS, Duthie F, Oien K, Hair J, Grützmann R, Maitra A, IacobuzioDonahue CA, Wolfgang CL, Morgan RA, Lawlor RT, Corbo V, Bassi C, Rusev B, Capelli P, Salvia R, Tortora G, Mukhopadhyay D, Petersen GM, Australian Pancreatic Cancer Genome Initiative., Munzy DM, Fisher WE, Karim SA, Eshleman JR, Hruban RH, Pilarsky C, Morton JP, Sansom OJ, Scarpa A, Musgrove EA, Bailey UM, Hofmann O, Sutherland RL, Wheeler DA, Gill AJ, Gibbs RA, Pearson JV, Waddell N, Biankin AV and Grimmond SM: Genomic analyses identify molecular subtypes of pancreatic cancer. Nature 531(7592): 4752, 2016. PMID: 26909576. DOI: 10.1038/nature16965

6 Witkiewicz AK, McMillan EA, Balaji U, Baek G, Lin WC, Mansour J, Mollaee M, Wagner KU, Koduru P, Yopp A, Choti MA, Yeo CJ, McCue P, White MA and Knudsen ES: Wholeexome sequencing of pancreatic cancer defines genetic diversity and therapeutic targets. Nat Commun 6: 6744, 2015. PMID: 25855536. DOI: $10.1038 /$ ncomms 7744

7 Jones S, Zhang X, Parsons DW, Lin JC, Leary RJ, Angenendt P, Mankoo P, Carter H, Kamiyama H, Jimeno A, Hong SM, Fu B, Lin MT, Calhoun ES, Kamiyama M, Walter K, Nikolskaya T, Nikolsky Y, Hartigan J, Smith DR, Hidalgo M, Leach SD, Klein AP, Jaffee EM, Goggins M, Maitra A, IacobuzioDonahue C, Eshleman JR, Kern SE, Hruban RH, Karchin R, Papadopoulos N, Parmigiani G, Vogelstein B, Velculescu VE and Kinzler KW: Core signaling pathways in human pancreatic cancers revealed by global genomic analyses. Science 321(5897): 1801-1806, 2008. PMID: 18772397. DOI: 10.1126/ science. 1164368

8 Cicenas J, Kvederaviciute K, Meskinyte I, Meskinyte-Kausiliene E, Skeberdyte A and Cicenas J: KRAS, TP53, CDKN2A, SMAD4, BRCA1, and BRCA2 mutations in pancreatic cancer. Cancers (Basel) 9(5): 42, 2017. PMID: 28452926. DOI: 10.3390/cancers 9050042

9 Takahashi M, Hori M, Mutoh M, Wakabayashi K and Nakagama $\mathrm{H}$ : Experimental animal models of pancreatic carcinogenesis for prevention studies and their relevance to human disease. Cancers (Basel) 3(1): 582-602, 2011. PMID: 24212630. DOI: 10.3390/ cancers 3010582

10 Kuno T, Takahashi S, Tomita H, Hisamatsu K, Hara A, Hirata A, Kobayashi H and Mori H: Preventive effects of fermented brown rice and rice bran against $\mathrm{N}$-nitrosobis (2-oxopropyl) amine-induced pancreatic tumorigenesis in male hamsters. Oncol Lett 10(6): 3377-3384, 2015. PMID: 26788138. DOI: 10.3892/ ol.2015.3809

11 Okamura T, Umemura T, Inoue T, Tasaki M, Ishii Y, Nakamura Y, Park EY, Sato K, Matsuo T, Okamoto S, Nishikawa A and Ogawa K: Chemopreventive effects of 4-methylthio-3-butenyl Isothiocyanate (Raphasatin) but not curcumin against pancreatic carcinogenesis in hamsters. J Agric Food Chem 61(9): 21032108, 2013. PMID: 23387327. DOI: 10.1021/jf3003174

12 Kuroiwa Y, Nishikawa A, Kitamura Y, Kanki K, Ishii Y, Umemura $\mathrm{T}$ and Hirose M: Protective effects of benzyl isothiocyanate and sulforaphane but not resveratrol against initiation of pancreatic carcinogenesis in hamsters. Cancer Lett 241(2): 275-280, 2006. PMID: 16386831. DOI: 10.1016/j.canlet.2005.10.028

13 Majima T, Tsutsumi M, Nishino H, Tsunoda T and Konishi Y: Inhibitory effects of beta-carotene, palm carotene, and green tea polyphenols on pancreatic carcinogenesis initiated by $\mathrm{N}$ nitorsobis(2-oxopropyl)amine in Syrian golden hamsters. 
Pancreas 16(1): 13-18, 1998. PMID: 9436857. DOI: 10.1097/ 00006676-199801000-00003

14 Asai A, Yonekura L and Nagao A: Low bioavailability of dietary epoxyxanthophylls in humans. Br J Nutr 100(2): 273-277, 2008. PMID: 18186952. DOI: 10.1017/S0007114507895468

15 Yonekura L, Kobayashi M, Terasaki M and Nagao A: Ketocarotenoids are the major metabolites of dietary lutein and fucoxanthin in mouse tissues. J Nutr 140(10): 1824-1831, 2010. PMID: 20739451. DOI: 10.3945/jn.110.126466

16 Nishino H, Murakoshi M, Tokuda H and Satomi Y: Cancer prevention by carotenoids. Arch Biochem Biophys 483(2): 165168, 2009. PMID: 18848517. DOI: 10.1016/j.abb.2008.09.011

17 Chen W, Zhang H and Liu Y: Anti-inflammatory and apoptotic signaling effect of fucoxanthin on benzo(A)pyrene-induced lung cancer in mice. J Environ Pathol Toxicol Oncol 38(3): 239-251, 2019. PMID: 31679311. DOI: 10.1615/JEnvironPatholToxicol Oncol.2019030301

18 Garg S, Afzal S, Elwakeel A, Sharma D, Radhakrishnan N, Dhanjal JK, Sundar D, Kaul SC and Wadhwa R: Marine carotenoid fucoxanthin possesses anti-metastasis activity: Molecular evidence. Mar Drugs 17(6): 338, 2019. PMID: 31195739. DOI: $10.3390 / \mathrm{md} 17060338$

19 Jin Y, Qiu S, Shao N and Zheng J: Fucoxanthin and tumor necrosis factor-related apoptosis-inducing ligand (TRAIL) synergistically promotes apoptosis of human cervical cancer cells by targeting PI3K/Akt/NF-kB signaling pathway. Med Sci Monit 24: 11-18, 2018. PMID: 29291370. DOI: 10.12659/msm.905360

$20 \mathrm{Yu}$ RX, Yu RT and Liu Z: Inhibition of two gastric cancer cell lines induced by fucoxanthin involves downregulation of Mcl-1 and STAT3. Hum Cell 31(1): 50-63, 2018. PMID: 29110251. DOI: $10.1007 / \mathrm{s} 13577-017-0188-4$

21 Liu Y, Zheng J, Zhang Y, Wang Z, Yang Y, Bai M and Dai Y: Fucoxanthin activates apoptosis via inhibition of $\mathrm{PI} 3 \mathrm{~K} / \mathrm{Akt} / \mathrm{mTOR}$ pathway and suppresses invasion and migration by restriction of $\mathrm{p} 38$-MMP-2/9 pathway in human glioblastoma cells. Neurochem Res 41(10): 2728-2751, 2016. PMID: 27394418. DOI: 10.1007/s11064-016-1989-7

22 Lopes FG, Oliveira KA, Lopes RG, Poluceno GG, Simioni C, Gabriel DSP, Bauer CM, Maraschin M, Derner RB, Garcez RC, Tasca CI and Nedel CB: Anti-cancer effects of fucoxanthin on human glioblastoma cell line. Anticancer Res 40(12): 67996815, 2020. PMID: 33288573. DOI: 10.21873/anticanres.14703

23 Kotake-Nara E, Terasaki M and Nagao A: Characterization of apoptosis induced by fucoxanthin in human promyelocytic leukemia cells. Biosci Biotechnol Biochem 69(1): 224-227, 2005. PMID: 15665492. DOI: 10.1271/bbb.69.224

24 Terasaki M, Maeda H, Miyashita K, Tanaka T, Miyamoto S and Mutoh M: A marine bio-functional lipid, fucoxanthinol, attenuates human colorectal cancer stem-like cell tumorigenicity and sphere formation. J Clin Biochem Nutr 61(1): 25-32, 2017. PMID: 28751806. DOI: 10.3164/jcbn.16-112

25 Terasaki M, Maeda H, Miyashita K and Mutoh M: Induction of anoikis in human colorectal cancer cells by fucoxanthinol. Nutr Cancer 69(7): 1043-1052, 2017. PMID: 28990814. DOI: $10.1080 / 01635581.2017 .1339814$

26 Terasaki M, Iida T, Kikuchi F, Tamura K, Endo T, Kuramitsu Y, Tanaka T, Maeda H, Miyashita K and Mutoh M: Fucoxanthin potentiates anoikis in colon mucosa and prevents carcinogenesis in AOM/DSS model mice. J Nutr Biochem 64: 198-205, 2019. PMID: 30530259. DOI: 10.1016/j.jnutbio.2018.10.007
27 Terasaki M, Mima M, Kudoh S, Endo T, Maeda H, Hamada J, Osada K, Miyashita K and Mutoh M: Glycine and succinic acid are effective indicators of the suppression of epithelialmesenchymal transition by fucoxanthinol in colorectal cancer stem-like cells. Oncol Rep 40(1): 414-424, 2018. PMID: 29693702. DOI: $10.3892 / o r .2018 .6398$

28 Yokoyama R, Kojima H, Takai R, Ohta T, Maeda H, Miyashita K, Mutoh M and Terasaki M: Effects of CLIC4 on fucoxanthinolinduced apoptosis in human colorectal cancer cells. Nutrition and Cancer: 1-10, 2020. DOI: 10.1080/01635581.2020.1779760

29 Mei C, Zhou S, Zhu L, Ming J, Zeng F and Xu R: Antitumor effects of laminaria extract fucoxanthin on lung cancer. Mar Drugs 15(2): 39, 2017. PMID: 28212270. DOI: 10.3390/ md15020039

30 Nomiyama $\mathrm{H}$, Osada $\mathrm{N}$ and Yoshie $\mathrm{O}$ : A family tree of vertebrate chemokine receptors for a unified nomenclature. Dev Comp Immunol 35(7): 705-715, 2011. PMID: 21295066. DOI: 10.1016/j.dci.2011.01.019

31 Huynh C, Dingemanse J, Meyer Zu Schwabedissen HE and Sidharta PN: Relevance of the CXCR4/CXCR7-CXCL12 axis and its effect in pathophysiological conditions. Pharmacol Res 161: 105092, 2020. PMID: 32758634. DOI: 10.1016/ j.phrs.2020.105092

32 Guo JC, Li J, Zhou L, Yang JY, Zhang ZG, Liang ZY, Zhou WX, You L, Zhang TP and Zhao YP: CXCL12-CXCR7 axis contributes to the invasive phenotype of pancreatic cancer. Oncotarget 7(38): 62006-62018, 2016. PMID: 27542220. DOI: 10.18632 /oncotarget. 11330

33 Heinrich EL, Lee W, Lu J, Lowy AM and Kim J: Chemokine CXCL12 activates dual CXCR4 and CXCR7-mediated signaling pathways in pancreatic cancer cells. J Transl Med 10: 68, 2012. PMID: 22472349. DOI: 10.1186/1479-5876-10-68

34 Fan H, Wang W, Yan J, Xiao L and Yang L: Prognostic significance of CXCR7 in cancer patients: a meta-analysis. Cancer Cell Int 18: 212, 2018. PMID: 30574021. DOI: 10.1186/s 12935-018-0702-0

35 Liu Z, Teng XY, Meng XP and Wang BS: Expression of stromal cell-derived factor 1 and CXCR7 ligand receptor system in pancreatic adenocarcinoma. World J Surg Oncol 12: 348, 2014. PMID: 25407240. DOI: 10.1186/1477-7819-12-348

36 Gebauer F, Tachezy M, Effenberger K, von Loga K, Zander H, Marx A, Kaifi JT, Sauter G, Izbicki JR and Bockhorn M: Prognostic impact of CXCR4 and CXCR7 expression in pancreatic adenocarcinoma. J Surg Oncol 104(2): 140-145, 2011. PMID: 21520098. DOI: 10.1002/jso.21957

37 Buchheit CL, Weigel KJ and Schafer ZT: Cancer cell survival during detachment from the ECM: multiple barriers to tumour progression. Nat Rev Cancer 14(9): 632-641, 2014. PMID: 25098270. DOI: $10.1038 / \mathrm{nrc} 3789$

38 Paoli P, Giannoni E and Chiarugi P: Anoikis molecular pathways and its role in cancer progression. Biochim Biophys Acta 1833(12): 3481-3498, 2013. PMID: 23830918. DOI: 10.1016/ j.bbamcr.2013.06.026

39 Horbinski C, Mojesky C and Kyprianou N: Live free or die: tales of homeless (cells) in cancer. Am J Pathol 177(3): 10441052, 2010. PMID: 20639456. DOI: 10.2353/ajpath.2010. 091270

40 DeMali KA, Wennerberg K and Burridge K: Integrin signaling to the actin cytoskeleton. Curr Opin Cell Biol 15(5): 572-582, 2003. PMID: 14519392. DOI: 10.1016/s0955-0674(03)00109-1 
41 Ridley AJ, Schwartz MA, Burridge K, Firtel RA, Ginsberg MH, Borisy G, Parsons JT and Horwitz AR: Cell migration: integrating signals from front to back. Science 302(5651): 17041709, 2003. PMID: 14657486. DOI: 10.1126/science.1092053

42 Ali MRK, Wu Y, Tang Y, Xiao H, Chen K, Han T, Fang N, Wu $\mathrm{R}$ and El-Sayed MA: Targeting cancer cell integrins using gold nanorods in photothermal therapy inhibits migration through affecting cytoskeletal proteins. Proc Natl Acad Sci USA 114(28): E5655-E5663, 2017. PMID: 28652358. DOI: 10.1073/pnas. 1703151114

43 Tsuboi M, Etoh H, Kato K, Nakatugawa H, Kato H, Maejima Y, Matsumoto G, Mori H, Hosokawa M, Miyashita K, Tokuda H, Suzuki N and Maoka T: Nitrocapsanthin and nitrofucoxanthin, respective products of capsanthin and fucoxanthin reaction with peroxynitrite. J Agric Food Chem 59(19): 10572-10578, 2011. PMID: 21899264. DOI: 10.1021/jf203493k
44 Rangarajan P, Subramaniam D, Paul S, Kwatra D, Palaniyandi K, Islam S, Harihar S, Ramalingam S, Gutheil W, Putty S, Pradhan R, Padhye S, Welch DR, Anant S and Dhar A: Crocetinic acid inhibits hedgehog signaling to inhibit pancreatic cancer stem cells. Oncotarget 6(29): 27661-27673, 2015. PMID: 26317547. DOI: 10.18632 oncotarget.4871

45 Jeong Y, Lim JW and Kim H: Lycopene Inhibits Reactive Oxygen Species-Mediated NF-kB Signaling and Induces Apoptosis in Pancreatic Cancer Cells. Nutrients 11(4), 2019. PMID: 30939781. DOI: 10.3390/nu11040762

Received January 8, 2021

Revised February 4, 2021

Accepted February 14, 2021 